\title{
Traditional application and modern pharmacological research of Eucommia ulmoides Oliv.
}

\author{
Lichuang Huang ${ }^{\dagger}$, Qiang Lyu ${ }^{\dagger}$, Wanying Zheng, Qiao Yang and Gang Cao* ${ }^{*}$
}

\begin{abstract}
As a Traditional Chinese Medicine, Eucommia ulmoides Oliv. has been used for the treatment of various diseases since ancient times, involving lumbar pain, knee pain, osteoporosis, hepatoprotection, paralysis, intestinal haemorrhoids, vaginal bleeding, abortion, spermatorrhoea, foot fungus, anti-aging etc. With the developing discovery of $E$. ulmoides extracts and its active components in various pharmacological activities, E. ulmoides has gained more and more attention. Up to now, E. ulmoides has been revealed to show remarkable therapeutic effects on hypertension, hyperglycemia, diabetes, obesity, osteoporosis, Parkinson's disease, Alzheimer's disease, sexual dysfunction. E. ulmoides has also been reported to possess antioxidant, anti-inflammatory, neuroprotective, anti-fatigue, anti-aging, anti-cancer and immunoregulation activities etc. Along these lines, this review summarizes the traditional application and modern pharmacological research of E. ulmoides, providing novel insights of E. ulmoides in the treatment of various diseases.
\end{abstract}

\section{Introduction}

Eucommia ulmoides Oliver, a plant belonging to the Eucommiaceae family, once widespread in the Northern Hemisphere, disappeared from other parts of Europe and North America due to the Quaternary Ice Age, and survives only in China [1]. As the utility and value of $E$. ulmoides has been recognized, the planting of E. ulmoides has been expanded. Hitherto the main production areas include the central and northern subtropical and southern temperate zones, and it has been successfully introduced to the United States, Britain, France, Hungary, Russia, Japan, Korea and other countries. E. ulmoides was first recorded in the Shen Nong Ben Cao Jing and has been used for over 2,000 years. The bark, leaves, seed, and the even male flowers are commonly utilized as medical remedies and performed for investigation of pharmacy. As a particularly well-known traditional

*Correspondence: caogang33@163.com

†Lichuang Huang and Qiang Lyu contributed equally to this work School of Pharmacy, Zhejiang Chinese Medical University, 548 Binwen Road, Hangzhou 310053, China
Chinese medicine, Chinese Pharmacopoeia documents the main functions of E. ulmoides bark are to nourish the liver and kidneys, strengthen the tendons and bones, and calm the fetus; $E$. ulmoides leaves are to nourish the liver and kidneys, strengthen the tendons and bones, which are similar to the bark and sometimes used as an alternative medicine.

Modern pharmacological studies reveal the remarkable therapeutic effects of E. ulmoides in hypertension, hyperglycemia, diabetes, obesity, osteoporosis, Parkinson's disease, Alzheimer's disease, aging, and sexual dysfunction. The iridoids and lignans are the major active constituents of E. ulmoides. Aucubin and geniposide isolated from $E$. ulmoides, both belonging to iridoids, have been extensively and profoundly studied for their biological activities involving anti-hypertension, anti-diabetes, neuroprotection, anti-cancer, anti-inflammatory, anti-osteoporotic, hepatoprotection and kidney protection etc. [2, $3]$, and these biological activities are possessed by the extract of $E$. ulmoides bark or leaves as well. Overall, the extensive biological activities made E. ulmoides a promising therapeutic to be widely used in clinical therapy. original author(s) and the source, provide a link to the Creative Commons licence, and indicate if changes were made. The images or other third party material in this article are included in the article's Creative Commons licence, unless indicated otherwise in a credit line to the material. If material is not included in the article's Creative Commons licence and your intended use is not permitted by statutory regulation or exceeds the permitted use, you will need to obtain permission directly from the copyright holder. To view a copy of this licence, visit http://creativecommons.org/licenses/by/4.0/. The Creative Commons Public Domain Dedication waiver (http://creativeco mmons.org/publicdomain/zero/1.0/) applies to the data made available in this article, unless otherwise stated in a credit line to the data. 
The aim of this review was to provide a comprehensive overview on the traditional application and the modern pharmacological research correlative with E. ulmoides, providing novel insights of $E$. ulmoides in the treatment of numerous diseases.

\section{Traditional application of $E$. ulmoides}

Eucommia ulmoides was first recorded in "Sheng Nong's Herbal Classic (Shen Nong Ben Cao Jing)" of the Han Dynasty in China, which deals with the alias, origin, properties, flavour and functions of $E$. ulmoides. Nowadays, E. ulmoides has been officially recognized as a medicinal plant and listed in Chinese Pharmacopeia. As recorded in ancient medical textbooks, E. ulmoides was recommended for the treatment of lumbar pain, knee pain, osteoporosis, improve learning and memory abilities, hepatoprotection, paralysis, intestinal haemorrhoids, vaginal bleeding, itching in the vaginal or scrotum, dampness and residual draining of urine, abortion, pregnancy bleeding, spermatorrhoea, soreness and pain in the feet, foot fungus, anti-aging (Fig. 1).

\section{Biological activities of $E$. ulmoides}

Cardiovascular system regulation activities of $E$. ulmoides Anti-hypertensive activities

Since the 1970s, the main pharmacological active compound, which termed $(+)$-pinoresinol di- $\beta$-D-glucoside (PG), for the anti-hypertensive activities of E. ulmoides have been investigated and reported [4]. In a subsequent clinical trial study reported in 1983, 18 men and 35 women with mild hypertension significantly decreased their blood pressure after a course of treatment with

Recommended therapeutic usages of $E$. ulmoides in ancient Chinese medical textbooks
(1) lumbar pain
(9) foot fungus
(2) knee pain
(10) hepatoprotection
(3) paralysis
(11) intestinal haemorrhoids
(4) abortion
(12) soreness and pain in the feet
(5) vaginal bleeding
(13) dampness and residual draining of urine
(6) anti-aging
(14) itching in the vaginal or scrotum
(7) osteoporosis
(15) pregnancy bleeding
(8) spermatorrhoea
(16) improve learning and memory abilities

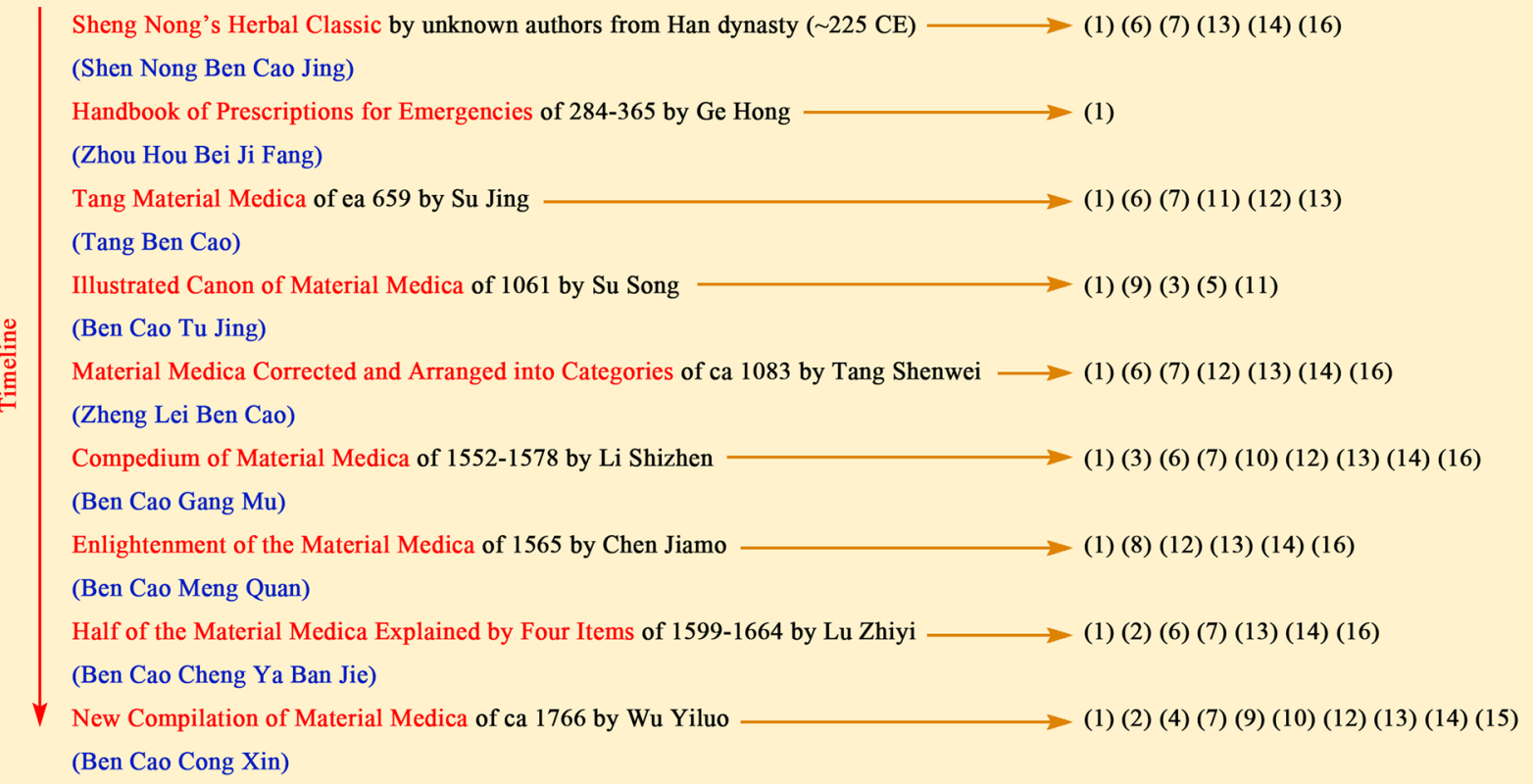

Fig. 1 Traditional applications of E. ulmoides recorded in ancient Chinese medical textbooks 
aqueous extract of $E$. ulmoides leaves, led to the potential of E. ulmoides as a promising candidate for the treatment of hypertensive diseases being identified [5].

A review conducted by $\mathrm{He}$ et al. outlined the research results of its pharmacological mechanism until 2014, that is, E. ulmoides exerts its function via inhibiting cAMP activity and $\mathrm{Ca}^{2+}$ internal flow (Analysis based on several studies from the 1970s to the 1990s), regulating NO and the renin-angiotensin system, relaxing blood vessels, as well as increasing coronary flow [6]. However, these summaries of $E$. ulmoides anti-hypertensive mechanism based on individual components instead of integral component tails are not absolute correct. A study conducted in 2010 revealed that $E$. ulmoides leaf lignans rather than iridoids capable of exerting antihypertensive activities in vivo. The lignans (150 and $300 \mathrm{mg} / \mathrm{kg}$ ) showed a dosedependent hypotensive effect in spontaneously hypertensive rats (SHRs), and decreased plasma renin activity and Ang II concentration. The lignans at $300 \mathrm{mg} / \mathrm{kg}$ dramatically increased plasma NO levels. Ex vitro trails showed the lignans $(0.05,0.2,0.4$ and $0.8 \mathrm{mg} / \mathrm{ml})$ relaxed mesenteric arteries in a dose-dependent manner. However, iridoids from $E$. ulmoides leaf $(15,30$ and $60 \mathrm{mg} / \mathrm{kg}$ by intravenous administration) showed no effect on blood pressure. Moreover, combination of lignans $(300 \mathrm{mg} /$ $\mathrm{kg})$ and Iridoids $(125 \mathrm{mg} / \mathrm{kg})$ by intragastric administration showed no synergistic effect [7]. Hence, although the earlier studies summarized by the review proposed that the compounds of iridoids, that is, asperuloside, geniposidic acid and genipin, exhibited varying degrees of anti-hypertensive effects in in vivo or in vitro trials, total iridoids from $E$. ulmoides leaf does not possess antihypertensive activity [6]. As we all know, phytomedicines consist of a complex range of compounds, and even in cases where the same fractions are isolated for in vivo or in vitro studies, the strength of their pharmacological activities are balanced by the counteracting pharmacological effects of the distinct compounds, especially in the case of in vivo assays, which involving complex biological regulatory mechanisms inherent in the organism.

In addition to E. ulmoides leaf, the lignans isolated from $E$. ulmoides bark showed similar anti-hypertensive activities in vivo [8-10]. Very recently, the anti-hypertensive effects of $E$. ulmoides male flowers were well documented. The aqueous extract of $E$. ulmoides male flowers $(0.05,0.10$ and $0.20 \mathrm{~g} / \mathrm{kg})$ dose-dependently reduced the blood pressure, and its effect via promoting expression of angiotensin-converting enzyme 2 (ACE2), of which function as a carboxypeptidase to catalyze the conversion of Ang II into Ang-(1-7). Subsequent trails were performed with ACE2 inhibitor DX600 and Ang-(1-7)-Mas receptor antagonist A-779, and the results showed the therapeutic effects of E. ulmoides male flowers in SHRs were reversed
[11]. This study indicated that the anti-hypertensive activities of E. ulmoides may via the activation of ACE2Ang-(1-7)-Mas signalling pathways, despite more investigations should be performed to establish whether this pathway is existing in E. ulmoides leaf or bark treatment.

Taken together, E. ulmoides has been identified as possessing anti-hypertensive activities for over forty years. Numerous individual components of the lignans and iridoids from E. ulmoides, involving PG, liriodendrin, $(+)$-syringaresinol, syringin, asperuloside, geniposidic acid and genipin, have been revealed to be able to lower blood pressure through inhibiting cAMP activity, $\mathrm{Ca}^{2+}$ internal flow, regulating $\mathrm{NO}$ and the renin-angiotensin system, relaxing blood vessels, and increasing coronary flow [6]. Intriguingly, the active constituent of E. ulmoides lignans showed anti-hypertensive activities in in vivo experiments, whereas the iridoids did not. Whether the opposite tendencies of action of the different components in the iridoids counteract the anti-hypertensive activities remains to be further investigated. Of note, the hypotensive effect of E. ulmoides lignans is not only exist in the pathological state of hypertension, but also shows hypotensive activities even in the normal physiological state in a dose-dependent manner [7]. Additionally, in parallel to the leaves and bark of E. ulmoides, its male flowers also exhibit anti-hypertensive activities. Future studies need to focus on whether interference with the ACE2Ang-(1-7)-Mas signalling pathway is present in both $E$. ulmoides leaves and bark in the therapeutic mechanism of hypertension.

\section{Other cardiovascular system regulation activities}

In the last decade, incidentally, in studies of the antihypertensive activities of E. ulmoides, it was discovered that lignans isolated from the bark were able to antagonize the expression of aldose reductase (AR) $(300 \mathrm{mg} /$ $\mathrm{kg}$ into SHRs), similarly to epalrestat $(100 \mathrm{mg} / \mathrm{kg})$, and thus exhibiting effects of against hypertensive vascular remodeling or against hypertensive renal injury [8-10]. $\mathrm{AR}$ is a multifunctional enzyme that reduces aldehydes. The correlation between AR and cardiovascular diseases particularly in the diabetic context has been summarized in an excellent review in 2010. Overall, AR is implicated in excess smooth muscle cell (SMC) growth, and its inhibition manifested as an amelioration of diabetes cardiac diseases and ischemia/reperfusion (I/R)-injured hearts [12]. Although there is still a deficiency of critical evidence that $E$. ulmoides lignans can act as an AR antagonist to improve cardiovascular disease, it is still a promising candidate for the treatment of diabetic heart disease or I/R-injured hearts.

Comparing to E. ulmoides extracts or active fraction groups, the individual active components of $E$. ulmoides 
have been more intensively studied in the treatment of cardiac diseases, involving cardiac hypertrophy, cardiac fibrosis and cardiac remodelling etc., and their associated mechanisms over the past year [13-21]. For instance, both in vivo and in vitro, aucubin has been found protecting against pressure overload-induced cardiac remodelling via $33-A R-n N O S$ cascades and it has been found protecting against myocardial infarction-induced cardiac remodeling via nNOS/NO-regulated oxidative stress [19, 21]. Meanwhile, geniposide has been revealed protecting against obesity-related cardiac injury through AMPK $\alpha-$ and sirtuin (Sirt1)-dependent mechanisms, etc. [16]. However, these effects have not yet been reported for $E$. ulmoides extracts or active fraction groups and needed further investigation to corroborate.

\section{Anti-osteoporotic activities of E. ulmoides}

Eucommia ulmoides has been unveiled to possess therapeutic effects on hypoestrogenemia after menopause result in osteoporosis, disuse-induced osteoporosis, senescence caused osteoporosis and lead affect bone composition and mineralization result in osteoporosis, and these therapeutic effects on osteoporotic models have been verified in ovariectomy (OVX) rats, hind limb suspension (HLS) rats, senescence-accelerated mice and lead acetate-induced bone loss rats. Mechanistic studies have revealed its anti-osteoporotic activities were referring to the modulation of the OPG/RANKL system in osteoblastic cells [22-27].

As early as 1998, a study reported the collagen synthesis promoting effect of E. ulmoides [28]. This biological activities of promoting collagen synthesis are favor for bone strengthening as modern studies have conclusively proven that a wide variety of genes encoding proteins involved in collagen synthesis, structure, processing, post-translational modification etc. have been showed to cause osteogenesis imperfect [29]. The above study also found that after fractionation of the methanolic extract of E. ulmoides leaves with n-hexane, AcOEt and Acetone sequentially, only methanol extract and Acetone fraction showed a dose-dependent pro-collagen synthesis effects in in vivo experiments in false aged model rats. Further in vivo trails have also shown that geniposidic acid and aucubin are the active components in the pro-collagen synthesis of E. ulmoides [28]. Similarly, a study reported in 2003 also adopted a fractionation approach with a view to screening $E$. ulmoides for bone-strengthening active components. Of note, methanol extract of E. ulmoides cortex was fractionated with n-hexane, chloroform, ethylacetate, butanol sequentially and performed with several in vitro trails. Details of the two studies in 1998 and 2003 are collated in Table 1[30]. As it showed, in study of $\mathrm{Ha}$ et al., each fractions or components participate in activities of osteoblast or osteoclast: (1) butanol fraction, aqueous fraction as well as geniposide and aucubin promoting proliferation and differentiation on osteoblast, (2) chloroform fraction and aucubin relating to the maturation of osteoblast, (3) chloroform, AcOEt fraction and geniposide show the effects on the synthesis of collagen participating in the matrix formation of osteoblast, (4) both chloroform and AcOEt fraction showed potent induction of growth hormone $(\mathrm{GH})$ release, through which approximately regulating bone maturation and remodeling, and (5) geniposidic acid and aucubin exhibited inhibition on osteoclast in dose-dependent manner. In line with anticipation, these effects on activities of osteoblast and GH release were present in Methanol extract. Collectively, these analyses suggest that the overall components of E. ulmoides cortex (extract) may be more effective in preventing and treating osteoporosis than the individual components.

OVX rats were extensively utilized for investigation of anti-osteoporosis activities of E. ulmoides. Reported in 2009 , it was found that ethanol extract $(100,300$, and $500 \mathrm{mg} / \mathrm{kg}$ ) of E. ulmoides cortex prevents the estrogen deficiency-induced bone loss and deterioration of trabecular microarchitecture, thereby maintaining biomechanical competence of bone in OVX rats [24]. Dietary supplementation of aqueous extract $(1.25 \%, 2.5 \%$, and $5 \%$ ) of roasted $E$. ulmoides leaf exhibited similar effects in OVX rats [26]. Of note, lignans of $E$. ulmoides have been considered as active fraction groups of anti-osteoporosis activities both in vivo and in vitro trails. In vivo, total lignans $(20,40$, or $80 \mathrm{mg} / \mathrm{kg})$ of E. ulmoides bark prevented decrease in biomechanical quality of femur, and prevented the deterioration of trabecular microarchitecture, which were in line with above studies. In vitro, the lignans treatment $(30-500 \mu \mathrm{g} / \mathrm{ml})$ induced primary osteoblastic cells proliferation and differentiation, and result in inhibition $(30,100,300 \mu \mathrm{g} / \mathrm{ml})$ of osteoclastogenesis through an increase in osteoprotegrin (OPG) and a decrease in RANKL expression [26]. This is an early literature that recognizes the anti-osteoporotic effects of E. ulmoides in relation to the OPG/RANKL system.

As well as in OVX rats, extracts of the E. ulmoides leaves or bark of have been shown to have anti-osteoporotic or bone-enhancing effects in animals in a variety of physiopathological states. Pan et al. in 2014 reported that ethanol extract $(300 \mathrm{mg} / \mathrm{kg})$ of the cortex exhibited preventing HLS-induced decrease of bone mass and the deterioration of trabecular microarchitecture, and helping to maintain the structural integrity and biomechanical quality of bone [22]. Another study has also demonstrated that ethanol extract (30 and $100 \mathrm{mg} / \mathrm{kg}$ ) of the cortex administration into adolescent female rats increased longitudinal bone growth rate and growth plate 


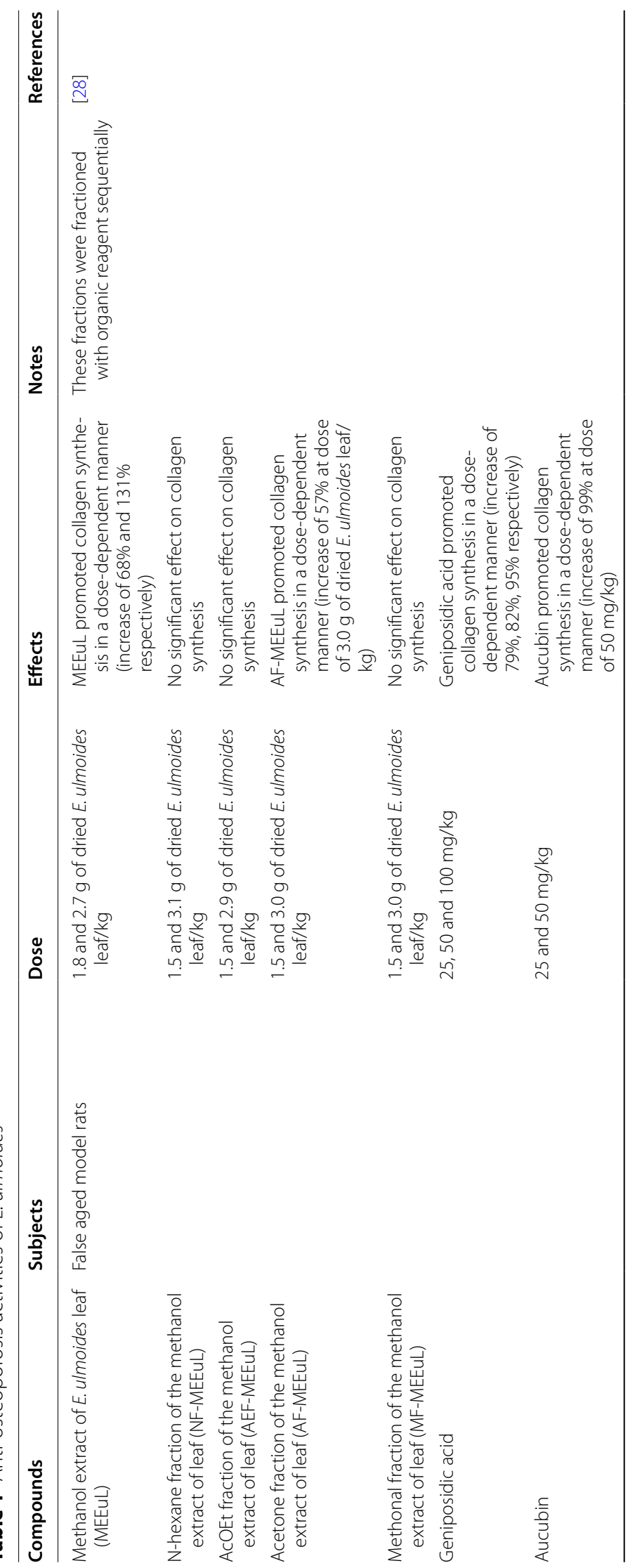




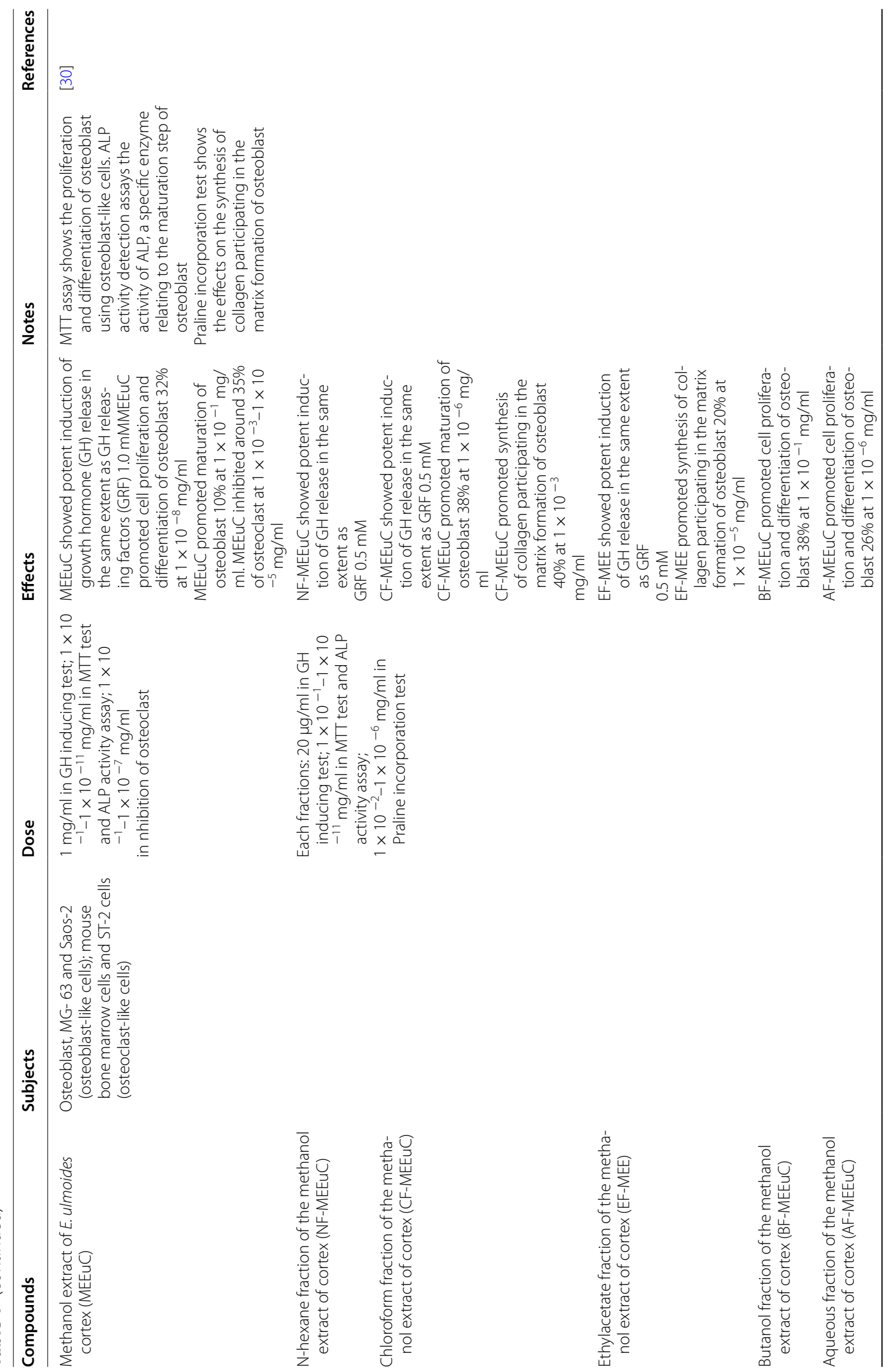




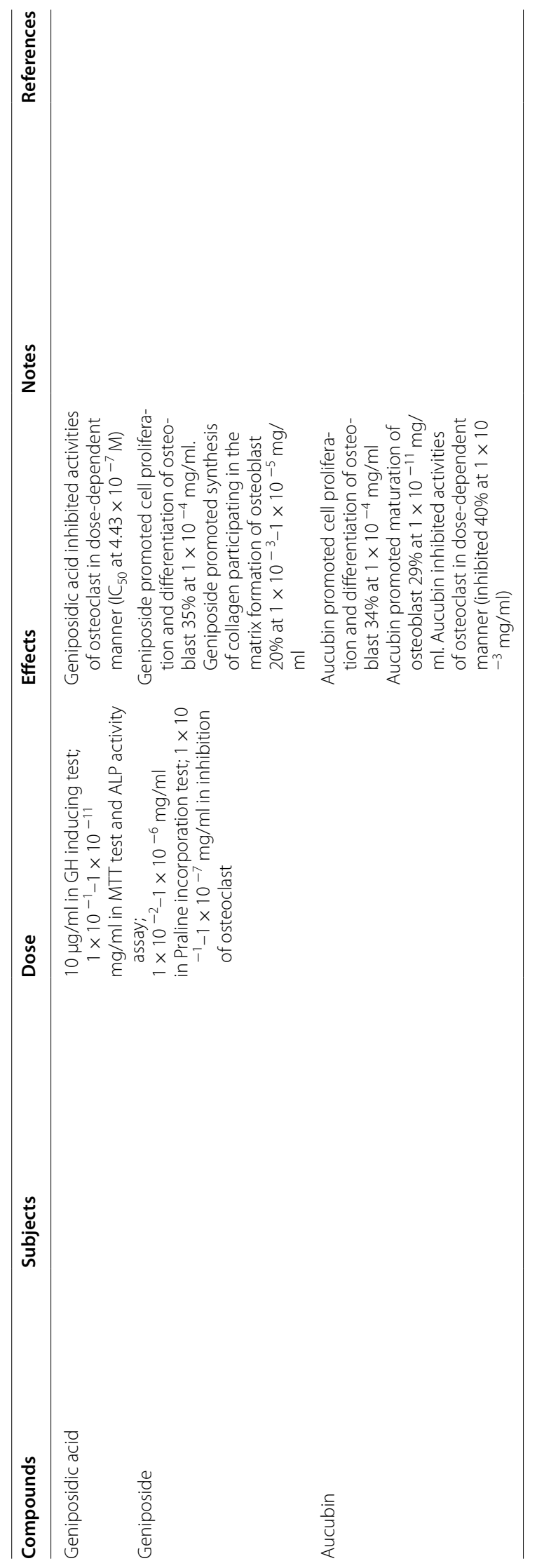


height, characterized by increasing BMP-2 and IGF-1 expressions in the proliferative and hypertrophic zones [31]. Ethanol extract ( 495 and $990 \mathrm{mg} / \mathrm{kg}$ ) of the leaf has also shown anti-osteoporotic effects in senescenceaccelerated mice P6 [27]. In lead acetate-induced bone loss rats, ethanol extract $(100 \mathrm{mg} / \mathrm{kg})$ of the cortex has been demonstrated in vivo trails to be anti-osteoporosis and increased OPG expression and OPG/RANKL ratio, which were in line with the mentioned above in vitro study. Nevertheless, there was no significant difference with or without treatment while refer to RANKL mRNA levels [23]. Whether the discrepancy in modulation of RANKL expression attribute to physiopathological context needed to be further investigated. By the way, total glycosides of $E$. ulmoides seed was demonstrated for the first time taken orally $(100 \mathrm{mg} / \mathrm{kg})$ increased bone density and bone strength of rat femur in specific-pathogen-free (SPF) female rats [32].

\section{Anti-inflammatory activities of E. ulmoides}

Last decade has extensively investigated the anti-inflammatory activities of $E$. ulmoides in distinct inflammatory disease models, involving septic inflammation and autoimmune diseases [33-37]. Of note, E. ulmoides may be a promising candidate in treating neuroinflammation, as the active components isolated from E. ulmoides, such as aucubin, has been profoundly demonstrated alleviating neuroinflammation in Parkinson's disease, Alzheimer's disease and seizures in vivo [38-40]. Except for the anti-neuroinflammatory activities covered in the neuroprotective section, the rest of the anti-inflammatory activities and its mechanisms were discussed in the following.

Aqueous extract of E. ulmoides bark has been extensively investigated for the treatment of lipopolysaccharide (LPS)-stimulation trails in vitro. In 2012, it was documented that the aqueous extract of bark treatment $(0.05,0.1$ and $0.5 \mathrm{mg} / \mathrm{ml})$ exert inhibition of LPS-induced NF- $\kappa \mathrm{B}$ activation, IкB- $\alpha$ degradation, and caspase- 1 activation in mice peritoneal macrophages [41]. In LPSstimulated BV-2 microglial cells, the aqueous extract of bark treatment $(2.5,5,10,25,50$ and $100 \mu \mathrm{g} / \mathrm{ml})$ downregulated the production of pro-inflammatory cytokines, mediators, and reactive oxygen species (ROS). Mechanistic investigation found its effects via modulating MAPKs, PI3K/Akt, and GSK-3 $\beta$, consequently suppressing NF- $\mathrm{KB}$ activation and inducing Nrf2-dependent HO-1 activation [34]. Indeed, oxygen-derived free radicals and high-energy oxidants manifested as mediators of inflammation, and currently antioxidant therapy has already been proposed into treatment of inflammation, which might appreciate the role that E. ulmoides plays in alleviating oxidative stress through the $\mathrm{Nrf} 2 / \mathrm{HO}-1$ in favor of anti-inflammation [42]. Lipopolysaccharide is belonging to the pathogen-associated molecular patterns (PAMPs) that can be detected by TLR4 therefore lead to subsequent signalling cause inflammation [43]. Of note, conducted by Koh et al., a critical study established that aqueous extract of $E$. ulmoides cortex exerted antiinflammation via interfering either of Myd88-dependent (suppress NF-kB, MAPK pathways) or independent pathway (suppress IFN- $\beta$ and STAT pathway) of TLR-4. The study as well demonstrated the extract, performed with Raw 264.7 cells, suppressed LPS-induced NO production $\left(\mathrm{IC}_{50}: 356.23 \mu \mathrm{g} / \mathrm{ml}\right)$ and downregulated expression of iNOS, COX-2, TNF- $\alpha$, IL-1 $\beta$ and PI3K/Akt/mTOR pathway in a dose-dependent manner [33].

Flavones and polysaccharide are active compound of E. ulmoides. In LPS-induced IPEC-J2 cells, flavones (10 $\mu \mathrm{g} / \mathrm{ml}$ ) from E. ulmoides leaf exhibited alleviating LPS induced damages, and mechanistic study unveiled the flavones harbor cytoprotective properties against inflammation approximately via PI3K/NF- $\mathrm{kB}$ signaling pathway [44]. In L02 cells transfected with TLR4 overexpression plasmid, polysaccharide $(8 \mu \mathrm{g} / \mathrm{ml})$ of E. ulmoides significantly inhibited the increasing expression of TLR4, MyD88, P-p65, and P-IкB- $\alpha$ proteins. The mechanisms referring to the inhibition TLR-4/NF- $\kappa B$ pathway activation by reducing HMGB1 release inhibition [45].

In 2016, first to show effects and mechanism of $E$. ulmoides on rheumatoid arthritis (RA), ethanol extract (dose of raw herbs, $2.7 \mathrm{~g} / \mathrm{kg}$ ) of the cortex in collageninduced arthritis (CIA) rats reduced the number of Th17positive cells and downregulated serum IL-17 expression and increased the anti-inflammatory effects of IL-10. In addition, it suppressed the proliferation of synoviocytes and prevented bone tissue damage which characterized by decreased RANKL mRNA whereas increased OPG mRNA expression [37]. The roles of Th17 cells and IL-17 in RA have been well reviewed recently $[46,47]$. Afterwards, conducted by the same team, ethanol extract of $E$. ulmoides cortex was fractionated with AcOEt and n-butyl alcohol sequentially, all fractions and extract (each dose of raw herbs at $4 \mathrm{~g} / \mathrm{kg}$ ) increased OPG/RANKL ratio, decreased MMP-9 expression, and inhibited IKK/NF- $\mathrm{KB}$ signaling pathway, whereas AcOEt fraction exhibited better improvement effect on OPG/RANKL system than others [35].

An emerging body of research on the anti-inflammatory activities of the active components of E. ulmoides has been conducted in the last five years. It was demonstrated that Aucubin suppressed LPS-induced inflammation and apoptosis in cardiac dysfunction mice, and protected against LPS-induced acute pulmonary injury through regulating Nrf2 and AMPK pathways both in vitro and in vivo $[13,48]$. Relatively, geniposide is more 
extensively utilized to investigate its anti-inflammatory effects and its mechanisms. Geniposide was found inhibiting NLRP3 inflammasome activation via autophagy in BV-2 microglial cells exposed to oxygen-glucose deprivation/reoxygenation [49]. Moreover, geniposide attenuates dextran sulfate sodium-induced colitis in mice via Nrf-2/ HO-1/NF- $\kappa B$ pathway [50]. Protocatechuic acid has also been revealed possessing anti-inflammatory activities in LPS-challenged piglets [51]. Although these findings do not directly indicate the anti-inflammatory effects of $E$. ulmoides, they provide a direction for the further investigation of the material basis of the anti-inflammatory activities and mechanisms of E. ulmoides.

\section{Antioxidant activities of $E$. ulmoides}

For more than 20 years, the antioxidant activities of $E$. ulmoides has been most extensively studied compared to other pharmacological activities. The leaves, bark and seed of E. ulmoides are all medicinal parts with antioxidant activities, and antioxidant assay in vitro including DPPH radical-scavenging abilities, ferric reducing antioxidant power and lipid peroxidation inhibition capacity have shown that the leaves are stronger than the bark, while the seeds are the least (Table 2) [52-54]. Total phenolic content and total flavonoid content are considered to correlative with the strength of the antioxidant activity of E. ulmoides. Indeed, the total phenolic and total flavonoid content of leaves, bark and seed are in line with the corresponding strength of antioxidant capacity. Other data obtained from tests such as influence of meat color, and metmyoglobin formation in raw pork patties or others comparing the strength of the antioxidant capacity of different medicinal parts of E. ulmoides are consistent with the above $[54,55]$. Besides, a study reported in 2013 has demonstrated the antioxidant activities of E. ulmoides male flowers and identified its main active compound as chlorogenic acid [56]. Of note, Zhang et al. have carried out a comprehensive assessment of the antioxidant capacity of $E$. ulmoides leaves collected monthly during the period of May to October in three years. Determination of active compound content and several antioxidant assays were performed for aqueous extracts of these sample, as well as active compounds therefore obtained a large amount of data. The results showed that August and May were indicated as the best months to harvest contribute to the high antioxidant activities [57].

Early in 1998, E. ulmoides has been demonstrated dose-dependently $(0-0.4 \mathrm{mg} / \mathrm{ml})$ inhibited the enzymatic and non-enzymatic lipid peroxidation of microsomal lipids in vitro, and the leaves extract was significantly more potent than the roasted bark extract and raw bark extract in either enzymatic or non-enzymatic peroxidation [58]. Afterwards, these three extracts were assessed on oxidative damage in biomolecules. All extracts (0-1.0 $\mathrm{mg} / \mathrm{ml}$ ) exhibited inhibitory activities in oxidation of deoxyribose in a concentration-dependent manner. In DNA protective trails, only leaf extract $(5,10 \mu \mathrm{g} / \mu \mathrm{l})$ exhibited reducing DNA strand-breaking from Fenton reaction. Further in Bleomycin-dependent DNA damage trails (once the extracts reduced the bleomycin- $\mathrm{Fe}^{3+}$ to bleomycin- $\mathrm{Fe}^{2+}$, DNA damage would occur), the results showed the three extracts of E. ulmoides had no significant prooxidant effect while facing bleomycin- $\mathrm{Fe}^{3+}$ and the leaf extract could chelate iron ions but had no significant ability to reduce $\mathrm{Fe}^{3+}$ to $\mathrm{Fe}^{2+}$. These analyses indicated $E$. ulmoides exert antioxidant activities via scavenging hydroxyl radical, function as chelating agent [59].

Over the past two decades, in complement to the above assessment of antioxidant activities, the favorable antioxidant activities of E. ulmoides has been demonstrated in biological in vivo experiments, with validity against oxidative stress in gastric mucosal injury, chronic hepatotoxicity, diabetes complications, lead-induction, obesity, I/R induced renal and hepatic toxicity etc. [45, 60-65]. Aqueous extract of $E$. ulmoides leaves has been demonstrated been therapeutic on water and $\mathrm{VC}$-deficient diets induced gastric mucosal injury pigs. The extract administration $(0.5,1.0$ and $2.0 \mathrm{~g} / \mathrm{kg})$ suppressed gastric intramucosal thiobarubiturate reactive substances (TBARS) levels, and decreased intramucosal levels of BrdU, 8-OHdG, ssDNA and TUNEL, all of which correlate with oxidative stressinduced DNA adducts and strand breaks [65]. Herein, it is pertinent to mention that there are multiple criteria for evaluating tissue levels of oxidative stress, such as superoxide dismutase (SOD), an antioxidant metalloenzyme that catalyzes the disproportionation of superoxide anion radicals to produce $\mathrm{O}_{2}$ and $\mathrm{H}_{2} \mathrm{O}_{2}$; catalase (CAT), its main role is to catalyze the decomposition of $\mathrm{H}_{2} \mathrm{O}_{2}$ into $\mathrm{H}_{2} \mathrm{O}$ and $\mathrm{O}_{2}$; malondialdehyde (MDA), a stable metabolite of the free radical-mediated lipid peroxidation cascade; as well as glutathione (GSH) and its functionally related enzymes, an essential antioxidant in the body, it is able to scavenge free radicals in the body. Their relevant functions can be referred to other excellent reviews [66-69]. Indeed, these criteria have been widely utilized in in vivo experiments to evaluate the antioxidant activity of E. ulmoides. In $\mathrm{CCl}_{4}$-induced chronic hepatotoxicity rats, aqueous extract $(0.1,0.5$, and $1.0 \mathrm{~g} / \mathrm{kg})$ of $E$. ulmoides leaves exhibited increasing GSH content, GSH peroxidase (GPH-Px), GSH reductase (GR) and GSH S-transferase (GST) activities, whereas decreased MDA content in liver. In this context, protocatechuic acid (0.1 $\mathrm{g} / \mathrm{kg}$ ) showed similar effects [61]. In type 2 diabetic mice, aqueous extract $(0.187 \mathrm{~g} / 100 \mathrm{~g}$ of diet) of leaves treatment increased erythrocyte SOD, CAT, GSH-Px activities, 
Table 2 Antioxidant activities of E. ulmoides

\begin{tabular}{|c|c|c|c|c|c|}
\hline Compounds & Subjects & Chemical composition & Effects & Notes & References \\
\hline $\begin{array}{l}\text { Ethanol extract of E. ulmo- } \\
\text { ides leaf (EEEuL) }\end{array}$ & $\begin{array}{l}\text { DPPH radical-cavenging; } \\
\mathrm{Fe}^{2+} \text {-chelating ability; } \\
\text { Lipid peroxidation }\end{array}$ & $\begin{array}{l}\text { Total phenolic content: } \\
\text { mg CAE/g. Geniposidic } \\
\text { acid: } 2.14 \pm 0.04 \text { mg/g. } \\
\text { Epicatechin: } 1.93 \pm 0.05 \\
\text { mg/g. } \\
\text { Chlorogenic acid: } 8.45 \pm \\
0.9 \text { mg/g. }\end{array}$ & $\begin{array}{l}\mathrm{EC}_{50} \text { of DPPH radical-scav- } \\
\text { enging: } 1.35 \pm 0.03 \mathrm{mg} / \\
\text { ml } \\
\mathrm{EC}_{50} \text { of } \mathrm{Fe}^{2+} \text {-chelating } \\
\text { ability: } \text { not detectable } \\
\mathrm{EC}_{50} \text { of Lipid peroxidation: } \\
16.74 \pm 0.09 \mathrm{mg} / \mathrm{ml}\end{array}$ & $\begin{array}{l}\text { Total phenolic content } \\
\text { as chlorogenic acid } \\
\text { equivalents (CAE) }\end{array}$ & [53] \\
\hline $\begin{array}{l}\text { Ethanol extract of E. ulmo- } \\
\text { ides leaf (EEEuL) }\end{array}$ & $\begin{array}{l}\text { DPPH radical- scavenging; } \\
\text { ferric reducing antioxi- } \\
\text { dant power (FRAP); lipid } \\
\text { peroxidation inhibition } \\
\text { capacity }\end{array}$ & $\begin{array}{l}\text { Total Phenolics Content } \\
\text { (TPC): } \\
\text { 94.46 } \pm 17 \text { mg of GAE/g } \\
\text { Total Flavonoids Content } \\
\text { (TFC): } \\
61.36 \pm 0.59 \mathrm{mg} \text { of CE/g. } \\
\text { Chlorogenic acid: } \\
18.39 \pm 0.09 \mathrm{mg} / \mathrm{g} \\
\text { Caffeic acid: } \\
2.55 \pm 0.08 \mathrm{mg} / \mathrm{g} \\
\text { Protocatechuic acid: } \\
1.60 \pm 0.03 \mathrm{mg} / \mathrm{g} \\
\text { Rutin: } 9.99 \pm 0.07 \mathrm{mg} / \mathrm{g} \\
\text { Quercetin: } \\
3.51 \pm 0.05 \mathrm{mg} / \mathrm{g} \\
\text { Kaempferol: } \\
1.10 \pm 0.04 \mathrm{mg} / \mathrm{g}\end{array}$ & $\begin{array}{l}\text { DPPH scavenging activity: } \\
81.40 \pm 3.63 \% \\
\text { Ferric reducing power } \\
\mathrm{EC}_{1}: 0.72 \pm 0.02 \mathrm{mg} / \mathrm{ml} \\
\text { Lipid peroxidation } \\
\text { inhibition capacity: } \\
43.58 \pm 3.29 \%\end{array}$ & $\begin{array}{l}\text { Total phenolic content } \\
\text { as gallic acid (GAE) } \\
\text { equivalents } \\
\text { Total Flavonoids Con- } \\
\text { tent (TFC) as catechin } \\
\text { equivalents (CE) } \\
\text { equivalents }\end{array}$ & [54] \\
\hline $\begin{array}{l}\text { Ethanol extract of } E \text {. } \\
\text { ulmoides roasted bark } \\
\text { (EEEuRB) }\end{array}$ & & $\begin{array}{l}\text { Total Phenolics Content } \\
\text { (TPC): } \\
40.07 \pm 0.45 \mathrm{mg} \text { of GAE/g } \\
\text { Total Flavonoids Content } \\
\text { (TFC): } \\
16.84 \pm 0.20 \mathrm{mg} \text { of CE/g. } \\
\text { Chlorogenic acid: } \\
7.38 \pm 0.12 \mathrm{mg} / \mathrm{g} \\
\text { Caffeic acid: } \\
1.54 \pm 0.05 \mathrm{mg} / \mathrm{g} \\
\text { Protocatechuic acid: } \\
1.02 \pm 0.06 \mathrm{mg} / \mathrm{g} \\
\text { Rutin: } 2.46 \pm 0.05 \mathrm{mg} / \mathrm{g} \\
\text { Quercetin: } \mathrm{not} \text { detect- } \\
\text { able Kaempferol: not } \\
\text { detectable }\end{array}$ & $\begin{array}{l}\text { DPPH scavenging activity: } \\
16.72 \pm 0.25 \% \\
\text { Ferric reducing power } \\
\mathrm{EC}_{1}: 2.81 \pm 0.09 \mathrm{mg} / \mathrm{ml} \\
\text { Lipid peroxidation } \\
\text { inhibition capacity: } \\
26.71 \pm 2.21 \%\end{array}$ & & \\
\hline $\begin{array}{l}\text { Ethanol extract of E. ulmo- } \\
\text { ides seed (EEEuS) }\end{array}$ & & $\begin{array}{l}\text { Total Phenolics Content } \\
\text { (TPC): } \\
19.11 \pm 0.12 \mathrm{mg} \text { of GAE/g } \\
\text { Total Flavonoids Content } \\
\text { (TFC): } \\
7.97 \pm 0.11 \mathrm{mg} \text { of CE/g. } \\
\text { Chlorogenic acid: } \\
0.67 \pm 0.01 \mathrm{mg} / \mathrm{g} \\
\text { Caffeic acid: not detect- } \\
\text { able. Protocatechuic } \\
\text { acid: } 0.26 \pm 0.03 \mathrm{mg} / \mathrm{g} \\
\text { Rutin: not detectable. } \\
\text { Quercetin: not detect- } \\
\text { able } \\
\text { Kaempferol: not detect- } \\
\text { able }\end{array}$ & $\begin{array}{l}\text { DPPH scavenging activity: } \\
7.65 \pm 0.20 \% \\
\text { Ferric reducing power } \\
E_{1}: 8.43 \pm 0.75 \mathrm{mg} / \mathrm{ml} \\
\text { Lipid peroxidation } \\
\text { inhibition capacity: } \\
25.10 \pm 1.37 \%\end{array}$ & & \\
\hline
\end{tabular}


Table 2 (continued)

\begin{tabular}{|c|c|c|c|c|}
\hline Compounds & Subjects & Chemical composition & Effects & References \\
\hline $\begin{array}{l}\text { Aqueous extract of } E \text {. } \\
\text { ulmoides leaf (AEEuL) }\end{array}$ & DPPH radical-scavenging & $\begin{array}{l}\text { Geniposidic acid Caffeic } \\
\text { acid Chlorogenic acid } \\
\text { Ferulic acid } \\
\text { Quercetin 3-O-sambubio- } \\
\text { side Rutin } \\
\text { Isoquercitrin Ascorbic acid }\end{array}$ & 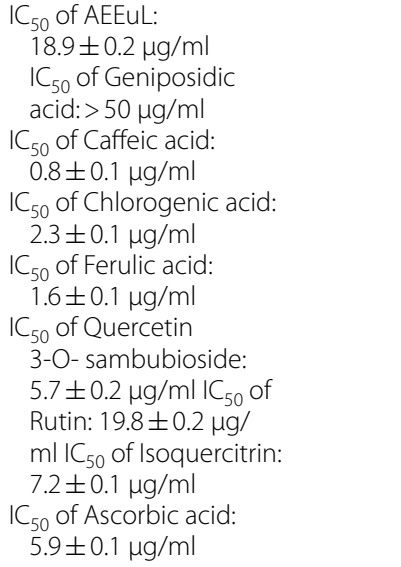 & [52] \\
\hline
\end{tabular}

whereas it showed no effects on erythrocyte GR activities. The treatment also showed no effects on SOD, GSH$\mathrm{Px}$, and GR activities in liver and kidney but decreased levels of hydrogen peroxide and lipid peroxide in erythrocytes, liver, and kidney [61].

E. ulmoides leaves extracts obtained by other methods have also been investigated. In vitro, in rat osteoblastic MC3T3-E1 cells with $\mathrm{H}_{2} \mathrm{O}_{2}$-induced apoptosis, ethanol extract of $E$. ulmoides leaf restrained oxidative damage and increased cell survival rate in a dose-dependent manner, with $\mathrm{EC}_{50}: 25 \mu \mathrm{g} / \mathrm{ml} \mathrm{EC}_{50}$ of downregulating caspases 3, 6, 7, and 9 expression ranging from 12.5 to $25 \mu \mathrm{g} /$ $\mathrm{ml}$ [70]. In vivo, performed with piglets, extract $(250 \mathrm{mg} /$ $\mathrm{kg}$, eucomman $\geq 20.00 \%$, flavone $\geq 8.00 \%$ and chlorogenic acid $\geq 5.00 \%$ ) of the leaves increased total SOD and GSH-Px in serum and liver. Mechanistic trails unveiled the antioxidant activities approximately be related to the upregulation of Nrf2/TNF- $\alpha$ and the activation of the Nrf2 signalling pathway [71].

The antioxidant activities of various groups of active components of $E$. ulmoides are also well documented. In male fattening lambs, polyphenolic (supplementation with 5 and $10 \mathrm{~g} / \mathrm{kg}$ of diet) extracted from E. ulmoides leaves Increased SOD, GSH-Px in serum and GSH-Px in liver, whereas decreased MDA content in serum and liver [63]. In streptozocin-induced diabetic mice, lignans (20 $\mathrm{mg} / \mathrm{kg}$ ) from E. ulmoides leaves upregulated the activity of oxidative stress-related enzymes, involving CAT, GSH-Px, and SOD. Mechanistic investigations revealed the lignans could activate $\mathrm{Nrf} 2 / \mathrm{HO}-1$ signaling to combat against oxidative stress [72]. In diquat-challenged weaned piglets, mechanistic studies unveiled that flavones from E. ulmoides interfering through $\mathrm{Nrf2}$ signalling played an important role in regulating oxidative stress in the intestine. The treatment $(100 \mathrm{mg} / \mathrm{kg})$ decreased the oxidized glutathione (GSSG) concentration and GSSG/GSH ratio and it increased the protein expressions of nuclear Nrf2 and Keap1, mRNA expression of HO-1, NQO-1, GCLC in the small intestinal mucosa [73]. In blood flow blocking-induced hepatic I/R injury rats, polysaccharide (80, 160 and $320 \mathrm{mg} / \mathrm{kg}$ ) of E. ulmoides decreased ROS, MDA levels and increased SOD levels in liver [45]. In rabbits with $I / R$ induced renal toxicity, the polysaccharides $(300$ and $600 \mathrm{mg} / \mathrm{kg}$ ) increased SOD, CAT, GSH-Px and GR activities whereas decreased MDA content in the kidney [60]. Collectively, these documents provide direct evidence that the polyphenols, lignans, flavonoids and polysaccharides of $E$. ulmoides are the active components of the antioxidant activities.

As showed in Table 2, numerous active components, involving geniposidic acid, caffeic acid, chlorogenic acid, ferulic acid, quercetin 3-O-sambubioside, rutin, isoquercitrin, ascorbic acid, were capable of antioxidant activities. Their $\mathrm{IC}_{50}$ of DPPH radical scavenging capacity were assessed and listed in Table 2. Apart from that, geniposide, aucubin and PG have also been reported alleviating oxidative stress and their antioxidant effects through regulation of Nrf2/HO-1 pathways [38, 74-79]. They were probably the critical compounds in the mechanism of antioxidant potency formation in E. ulmoides, but not all of them. In nature, excessive oxidant challenge results in damage to biomolecules. Redox balance is maintained by prevention, interception, and repair, and concomitantly the regulatory potential of molecular thiol-driven master switches such as Nrf2/Keap1 or NF-kB/IкB is utilized for system-wide oxidative stress response [80]. Overall, although few studies have directly shown that the aqueous or ethanol extracts of the leaves or bark of $E$. 
ulmoides exert antioxidant effects by activating the Nrf2 pathway, studies on both the active fraction groups and the individual active ingredients of $E$. ulmoides have indicated that the Nrf2 pathway is an important target for the antioxidant effects of $E$. ulmoides.

\section{Neuroprotective activities of $E$. ulmoides}

Eucommia ulmoides has been established to have protective effect against oxidative stress-induced nerve cell death [81-83]. Both in vivo and invitro experiments proved that $E$. ulmoides possessing therapeutic effects on neurodegenerative diseases, involving Parkinson's disease and Alzheimer's disease [84-86].

Several in vitro studies revealed the neuroprotective activities of aqueous extract of $E$. ulmoides bark against oxidative stress. In $\mathrm{H}_{2} \mathrm{O}_{2}$-induced human SH-SY5Y neuroblastoma cells, the aqueous extract $(5,10$ and $20 \mu \mathrm{g} /$ $\mathrm{ml}$ ), in a dose-dependent manner, inhibited neuronal cell death corresponded to alterations in down-regulation of PARP cleavage and caspase- 3 cleavage, up-regulation of Bcl-2 and Bcl-xL activation, as well as the reduction of mitochondrial cytochrome $\mathrm{c}$ release. The treatment also attenuated $\mathrm{H}_{2} \mathrm{O}_{2}$-induced phosphorylation of JNK, p38MAPK, ERK1/2, and PI3K/Akt [81]. In 6-hydroxydopamine-induced (6-OHDA) SH-SY5Y cells, aqueous extract of the bark $(25,50$ and $100 \mu \mathrm{g} / \mathrm{ml})$ attenuated oxidative stress through suppressing activation of JNK, PI3K/Akt, GSK-3 $\beta$, and NF-KB pathways [82]. Lignans from $E$. ulmoides are effective components of neuroprotective activities. In glaucoma rats, the lignans treatment (20 $\mathrm{mg} / \mathrm{kg})$ prevented oxidative stress-induced ocular neuropathy role via regulating antioxidant enzymes (CAT, GSH-Px, and SOD) and anti-oxidative stress signaling, including the activation of AMPK and Nrf2-ARE signalling [83].

Alzheimer's disease, a form of dementia, is a slowly progressing disorder characterized by specific protein accumulations in the brain [87]. Documented in 2009, an in vitro study assessed the therapeutic effect of aqueous extract of E. ulmoides bark and leaves as well as their components on Alzheimer's disease. In amyloid- $\beta$ peptide $(\mathrm{A} \beta)_{25-35}$-induced PC-12 cells, both the extract of bark and leaves (each at $0.001-1 \mathrm{mg} / \mathrm{ml}$ ) antagonized $A \beta_{25-35}$-induced cytotoxicity in dose-dependent manner. Geniposidic acid $(0.1-100 \mu \mathrm{g} / \mathrm{ml})$ and chlorogenic acid $(1-100 \mu \mathrm{g} / \mathrm{ml})$ exhibited significant protective effects on the cytotoxicity of $A \beta_{25-35}$ and seemed to be main active components of E. ulmoides bark and leaves against Alzheimer's disease. Phenylpropanoid components from E. ulmoides, such as ethyl caffeate and pinoresinol diglucoside, and the flavonoid compounds neither rutin nor quercetin exhibited any cytoprotective effect. Mechanistic studies revealed the neuroprotective mechanisms of $E$. ulmoides extract and its active components referring to inhibiting excessive $\mathrm{Ca}^{2+}$ influx, reducing additional lactate dehydrogenase (LDH) leakage and rescuing viability loss [86]. Reported in 2010, a study performed both in vivo and in vitro has also proved the therapeutic effects of aqueous extract of the bark. In $A \beta_{25-35}$-induced learning and memory impairments mice, the extract $(5,10$ and $20 \mathrm{mg} / \mathrm{kg})$ treatment improved the induced learning and memory deficit as well as cognitive impairments. In vitro, the $\mathrm{IC}_{50}$ of the extract in inhibition of acetyl-cholinesterase (AChE) activity was $172 \mu \mathrm{g} / \mathrm{ml}$. Ex vivo, inhibition of AChE activity was found effective in the hippocampus and frontal bark [85]. This study indicated the therapeutic effects of aqueous extract of $E$. ulmoides bark via blocking AChE activity. However, there is no more indepth mechanistic investigation.

Parkinson disease is characterized by death of dopaminergic neurons in the substantia nigra and a pathologic hallmark, termed Lewy body, a neuronal inclusion consisting largely of $\alpha$-synuclein protein aggregations [88]. In 2015, a study proposed the mechanism of $E$. ulmoides treating Parkinson's disease might via ameliorating the ubiquitin-proteasome system (UPS). In 1-methyl-4-phenyl-1,2,3,6-tetrahydropyridine (MPTP)induced Parkinson's disease mice, ethanol extract (150, 300 and $600 \mathrm{mg} / \mathrm{kg}$ ) of E. ulmoides bark antagonized the loss of striatal neurotransmitters and relieved the associated anomaly in ambulatory locomotor activity induced by MPTP in dose-dependent manner. Further in vitro trails, performed with MG132-induced SHSY5Y cell lines, assessed the neuroprotective activities of the components isolated from E. ulmoides, involving botulin, wogonin, oroxylin A, geniposidic and aucubin. The results showed all the components (each at 10 $\mu \mathrm{M})$ attenuated $\mathrm{MPP}^{+}$-induced dysfunction of protease activity and reduced MG132-induced cytotoxicity [84].

In addition to the above, recent years, numerous studies have been conducted to investigate in depth the potency and mechanisms of the neuroprotective effects of the active components of $E$. ulmoides. For instance, aucubin $(50 \mathrm{mg} / \mathrm{kg})$ has been reported exerting neuroprotective effects against MPTP-induced Parkinsonian mice in part by reducing inflammation and preserving dopaminergic neurons [40]. Aucubin (50 and $100 \mathrm{mg} /$ $\mathrm{kg}$ ) has also been revealed inhibiting seizure activity in Pilocarpine (PILO)- induced mice and its action might be related to the reduction of neuroinflammation and the regulation of neurotransmission [39]. Other components of E. ulmoides involving geniposidic acid, pinoresinol diglucoside and macranthoin $G$ have well been documented with neuroprotective activities [89-92]. 


\section{Hypolipidemic activities of E. ulmoides}

Sufficient in vivo or in vitro studies have confirmed the ameliorative effect of the aqueous extract of $E$. ulmoides leaves or the ethanol extract of E. ulmoides on hyperlipidemia in non-alcoholic fatty liver disease (NAFLD) or acute liver injury, involving type 2 diabetic, obese and hepatotoxic hyperlipidemia [93-98]. Mechanistic studies found that E. ulmoides via down-regulation of mTOR signalling therefore enhancing lysosomal functions and promoting autophagy, result in promotion of liver fat metabolism and hepatoprotection, subsequently exert hypolipidemic effects [95].

Aqueous extract of $E$. ulmoides leaves is widely investigated in hypolipidemic studies. Early in 2006, it has been reported that aqueous extract $(0.187 \mathrm{~g} / 100 \mathrm{~g}$ diet $)$ of the leaves, in type 2 diabetic mice, significantly lowered the hepatic fatty acid synthase, 3-hydroxy-3-methylglutaryl CoA (HMG-CoA) reductase, acyl CoA: cholesterol acyltransferase (ACAT) activities and furthermore elevated the lipoprotein lipase activity in the skeletal muscle. The plasma and hepatic lipid content were reduced, characterized by lower cholesterol and triglyceride concentrations and the higher plasma high-density lipoprotein cholesterol (HDLC) level [98]. Similar downregulated effects in hepatic fatty acid synthase and HMG-CoA reductase activities as well as the HDLC/total cholesterol ratio were attained while high-fat diet (HFD)-induced hyperlipidemic hamsters were administrated with the aqueous extract of leaves $(0.187 \mathrm{~g} / 100 \mathrm{~g}$ diet $)$ [97]. Notably, the two studies above indicated aqueous extract of E. ulmoides leaves exert hypolipidemic effects via altering lipogenesis, fatty acid $\beta$-oxidation and cholesterol metabolism in the liver. Reported in 2010, the hypolipidemic mechanisms of the extract was hypothesized to transforming autonomic nerve activities and causing alteration in thermogenesis and body weight. Indeed, the intraduodenal injection of $1 \mathrm{mg}$ the extract into HFDinduce hyperlipidemic rats elevated epididymal white adipose tissue sympathetic nerve activity (WAT-SNA) and interscapular brown adipose tissue sympathetic nerve activity (BAT-SNA), whereas it decreased gastric vagal nerve activity (GVNA) [93]. Documented in 2019, a study unveiled that the treatment of aqueous extract (100 and $200 \mathrm{mg} / \mathrm{kg}$ ) of E. ulmoides leaves, in HFDinduced lipid dysmetabolism rats, exert hepatoprotective effects against steatosis, accompanied by suppression of ER stress, enhancing lysosomal function and increasing autophagic flux. This promoting autophagy of liver through downregulation of mTOR signalling pathway approximately be the mechanism of hypolipidemic effects of the extract in lipid dysmetabolism. Furthermore, in vitro trails performed with palmitate-induce HepG2 cells have established that both aucubin and geniposide (each at $25 \mu \mathrm{g} / \mathrm{mL}$ ) harbor hypolipidemic activities and similar with the aqueous extract $(50,100,250 \mu \mathrm{g} / \mathrm{mL})$, as the results showed the downregulation of mTOR signalling, alleviation of ER stress and promotion of autophagy [95].

In addition, it has been reported that chlorogenic acid (45.23\%)-enriched extract ( $25 \mathrm{mg} / \mathrm{L}$ ) of E. ulmoides improved the lipid metabolism by the transcriptional activating AMPK and inhibiting downstream targets, such as SREBP2 and HMGCR, to suppress the total cholesterol synthesis and total triacylglycerol levels in HepG2 cells. The $\mathrm{IC}_{50}$ of the extract on lipid accumulation is $59.2 \mathrm{mg} / \mathrm{L}$ [99]. Of note, the AMPK and TOR pathways are interlinked, opposing signaling pathways involved in sensing availability of nutrients and energy and regulation of cell growth [100]. Accordingly, it is worthwhile to investigate the modulation of two signalling pathways by extract of $E$. ulmoides.

The extract of $E$. ulmoides bark has also been investigated for its hypolipidemic activities. In $\mathrm{CCl}_{4}$-induced hepatic lipid accumulation rats, ethanol extract $(0.25$, 0.5 and $1 \mathrm{~g} / \mathrm{kg}$ ) of $E$. ulmoides bark exerted anti-hyperlipidemic effect via alleviation of ER stress and oxidative stress, which characterized by increase of lysosomal enzymes and hepatic GSH and MDA [94]. Another study, in HFD-induced hepatic dyslipidemia rats, has also proved the hypolipidemic activities of ethanol extract of E. ulmoides bark through improving lysosomal activities. Furthermore, invitro trails, performed with palmitateinduced human HepG2 hepatocytes, have shown the extract $(100 \mathrm{mg} / \mathrm{mL})$ of the bark inhibited palmitateinduced ER stress, reduced hepatic lipid accumulation [96].

\section{Other activities}

Eucommia ulmoides was also reported to possess other pharmacological activities involving anti-obesity, hypoglycemic, anti-diabetic, anti-cancer, immunoregulation, anti-fungal and bacteria, improve erectile, anti-fatigue and anti-aging activities (Fig. 2, involve the pharmacological activities mentioned above). Detailed information was summarized in this section.

\section{Anti-obesity activities of E. ulmoides}

One authoritative definition of obesity is a disproportionate body weight for height with an excessive accumulation of adipose tissue that is usually accompanied by mild, chronic, systemic inflammation [101]. As we have discussed in the section on hypolipidemic activities, extracts of E. ulmoides are able to promote the metabolism of lipids such as cholesterol and triglycerides in the liver. Indeed, these functions have the potential to promote the anti-obesity effects of E. ulmoides. Besides, there are also some reports that directly 


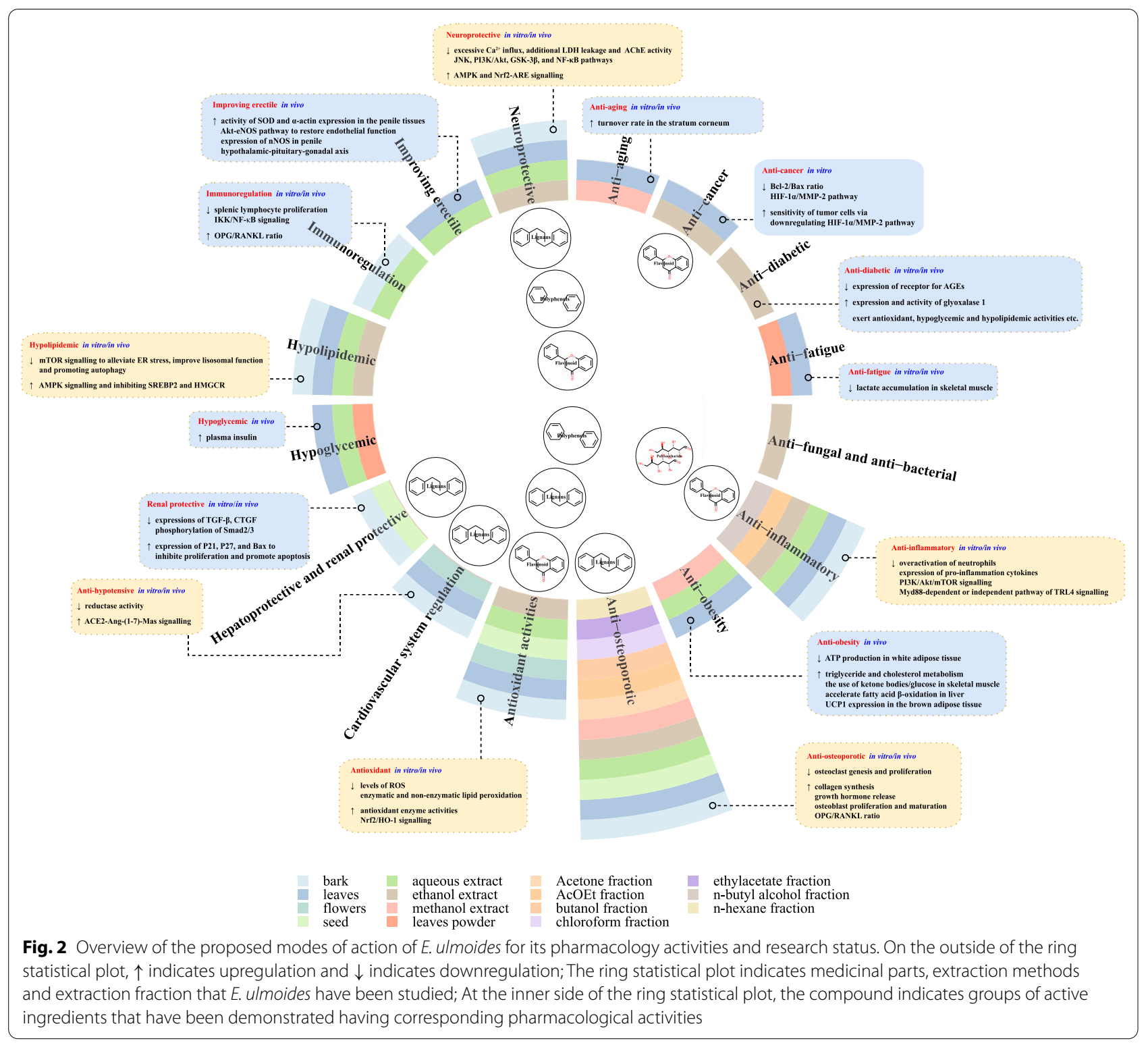

demonstrated the capacity of extracts of E. ulmoides to reduce the accumulation of body fat and promote the metabolism of substances and energy. Dietary supplementation with aqueous extract (diet containing 3\%) of roasted leaves or green leaf powder (diet containing 9\%) of E. ulmoides, administrated in HFD-induced rats, both minimized increases in body weight and visceral fat in a dose-dependent manner. Both treatments enhanced metabolic function across several organs, including diminishing ATP production in white adipose tissue, accelerating $\beta$-oxidation in liver and increasing the use of ketone bodies/glucose in skeletal muscle [102]. Similar results were obtained while treating mice with HFD containing $10 \%$ E. ulmoides leaves methanol extract. The treatment significantly inhibited body weight, white adipose tissue weight, plasma triglyceride levels and total cholesterol levels. These effects may attribute to asperuloside, which isolated from $E$. ulmoides leaves, as further trails with administration of asperuloside ( $0.1 \%$ dietary supplementation) exhibited analogous effects [103]. The anti-obesity activities and its mechanisms of asperuloside $(0.03 \%, 0.1 \%$ and $0.3 \%)$ has been compared with roasted E. ulmoides leaves aqueous extract (5\%). Exclusively, asperuloside administration resulted in increase of non-shivering thermogenesis due to uncoupling protein 1 (UCP1) expression in the brown adipose tissue. Asperuloside may act as a major compound in E. ulmoides, relating nearly all 
metabolic function across several organs, except for the activation of the brown adipose tissue UCP1-induced thermogenesis [104].

\section{Hypoglycemic activities of E. ulmoides}

The hypoglycaemic activities of E. ulmoides are seen in diabetic models, whereas E. ulmoides has no effect on blood glucose levels in normal physiological states. In streptozotocin-induced diabetic rats, E. ulmoides leaves aqueous extract $(0.187 \mathrm{~g} / 100 \mathrm{~g}$ diet $)$ or E. ulmoides powder $(1 \mathrm{~g} / 100 \mathrm{~g}$ diet $)$ supplementation treatment showed significant but quite small reduction in plasma glucose, however, occurred with simultaneous the increase in plasma insulin and C-peptide [105]. Another study acquired similar results in lowering blood glucose level as well as enhancing plasma insulin and C-peptide levels, as showed in type 2 diabetic model [98]. Of note, this enhancement of plasma insulin was pathological context dependent. Oral administration of roasted E. ulmoides leaves aqueous extract (500 and $1000 \mathrm{mg} /$ $\mathrm{kg}$ ) notably decreased plasma insulin without affecting blood glucose levels in fructose-drinking rats [106].

\section{Anti-diabetic activities of E. ulmoides}

Diabetes, a chronic degenerative disease, characterized by defective insulin secretion or impairment of its biological actions, or both, causing hyperglycemia and generally results in relatively specific long-term complications affecting the eyes, kidneys, and peripheral and autonomic nervous systems, accounting for more adult cases of vision loss, end-stage kidney disease, and amputations than any other disease [107]. In the section on pharmacological activities above, we have described the therapeutic effects of $E$. ulmoides on complications of diabetic models such as heart disease, oxidative stress, dyslipidemia, and hyperglycemia. Herein, we focus on the modulation of $E$. ulmoides on diabetic advanced glycation end-products (AGEs), and in following another section, the therapeutic effects of E. ulmoides on diabetic nephropathy will be discussed.

In streptozotocin-induced diabetic mice, the treatment of ethanol extract $(200 \mathrm{mg} / \mathrm{kg})$ of E. ulmoides bark did not change blood glucose and glycated hemoglobin (HbA1c) levels, whereas there was a significant increase in the protein expression and activity of glyoxalase 1, which detoxifies the AGE precursor, methylglyoxal. The treatment reduced periodic acid-Schiff (PAS)-positive staining, AGEs, methylglyoxal (MGO) accumulation in diabetic mice, and mechanistically, upregulated Nrf2 expression but downregulated expression of receptor for AGE [108].

\section{Hepatoprotective and renal protective activities of $E$. ulmoides}

In section of hypolipidemic activities, we have discussed the hepatoprotective role of E. ulmoides in NAFLD, mainly through downregulation of mTOR signaling thereby improving lysosomal function and promoting autophagy. The protective effects of E. ulmoides in acute liver injury have also been described. In the following, we mainly focus on the efficacy of $E$. ulmoides on nephropathy.

Administration of $E$. ulmoides seed ethanol extract $(1 \mathrm{~g} / \mathrm{kg})$ to streptozotocin-induced type 1-like diabetes in rats, significantly decreased the plasma levels of blood urea nitrogen, creatinine. The treatment markedly attenuated higher expressions of TGF- $\beta$ levels, connective tissue growth factor (CTGF), and reduced phosphorylation of $\mathrm{Smad} 2 / 3$ in streptozotocin-induced diabetes rats. However, the hyperglycemia-induced overexpression of STAT3 were not reversed [109]. Lignans from E. ulmoides bark were considered be highly pharmacologically active compounds, as both in vivo and in vitro experiments have demonstrated the renal protection against hypertensive renal injury. In SHRs, the lignans treatment $(300 \mathrm{mg} / \mathrm{kg})$ significantly decreased N-Acetyl$\beta$-D-glucosaminidase (NAG) enzyme activity, the ratio of albumin to urinary creatinine and the high expression of collagen type III. In vitro, the lignans (30 and 90 $\mathrm{mg} / \mathrm{L}$ ) inhibited the proliferation of Ang II-induced renal mesangial cells (RMCs) [9]. Another in vitro experiment demonstrated the lignans treatment $(20,40$, and 80 $\mathrm{mg} / \mathrm{L}$ ), in ang II-induced RMCs, play a protective role by inhibiting proliferation and promoting apoptosis through the upregulation expression of P21, P27, and Bax [110].

\section{Anti-cancer activities of E. ulmoides}

Several reports have demonstrated the therapeutic effects of E. ulmoides on carcinomas. A study showed that the $\mathrm{IC}_{50}$ of E. ulmoides leaves ethanol extract inhibiting MCF7 cell viability at $48 \mathrm{~h}$ and $24 \mathrm{~h}$ were about 8.2 and $11.2 \mathrm{mg} / \mathrm{mL}$, respectively, whereas the $\mathrm{IC}_{50}$ for purified chlorogenic acid (98.7\%) from E. ulmoides was only $0.31 \mathrm{mg} / \mathrm{mL}$ at $48 \mathrm{~h}$ and $0.73 \mathrm{mg} / \mathrm{mL}$ at $24 \mathrm{~h}$, much less than that for crude extract [111]. Conducted by Wang et al., the total flavonoid isolated from E. ulmoides leaves ethanol extract reduced the viability rate of glioblastomas cells in dose-dependent manner $(0-32.0 \mu \mathrm{g} /$ $\mathrm{mL}$ ). The $\mathrm{IC}_{50}$ and $\mathrm{LC}_{50}$ of E. ulmoides flavonoid were at 2.76 and $3.15 \mu \mathrm{g} / \mathrm{mL}$, respectively, showed more effective to inhibit glioblastomas, while comparing to normal human HA cells $\left(\mathrm{IC}_{50}\right.$ at $17.97 \mu \mathrm{g} / \mathrm{mL}, \mathrm{LC}_{50}$ at $4.71 \mu \mathrm{g} /$ $\mathrm{mL}$ ). In addition, the flavonoid at $2.0 \mu \mathrm{g} / \mathrm{mL}$ significantly reduced migration and invasion abilities of U251 
and U87 in glioblastomas cells. While the flavonoid in combination with radiotherapy, the results showed significantly increase apoptotic of glioblastomas cells, and further investigation found the combination treatment was correlative with the lowest ratio of $\mathrm{Bcl}-2 / \mathrm{Bax}$, comparing to merely radiotherapy or the flavonoid treatment group. Further analyses indicated an effect of enhancing the sensitivity of glioblastomas cells in radiotherapy by E. ulmoides flavonoid, which might refer to downregulating HIF-1 $\alpha /$ MMP-2 pathway, as the data showed the expressions of HIF- $1 \alpha$ and MMP- 2 were further reduced after the combination treatment [112]. In addition, Fujiwara et al. isolated a $\beta$-truxinate lignan from $E$. ulmoides leaves, termed, Eucommicin A, which showed excellent inhibitory activities on cancer stem cells (CSCs). Comparing to chlorogenic acid $\left(\mathrm{IC}_{50}=6900 \mu \mathrm{M}\right)$, Eucommicin A showed $\mathrm{IC}_{50}$ of inhibiting induced CSC-like (iCSCL)-10A viability at $55.0 \mu \mathrm{M}$ [113].

\section{Immunoregulation activities of $E$. ulmoides}

A research has been accomplished to explore the modulation of immune system by $E$. ulmoides bark aqueous extract and its active compound genipin. Both the extract $(40,100$ and $250 \mu \mathrm{g} / \mathrm{ml})$ and genipin $(10,20,50$ and $100 \mu \mathrm{M})$ exhibited suppressing the proliferation of primary splenic lymphocytes induced by concanavalin A (Con A) or LPS in dose-dependent manner, but not macrophage phagocytosis. In vivo, administration of E. ulmoides extract $(100,200$ and $500 \mathrm{mg} / \mathrm{kg}$ ) or genipin (10 and $30 \mathrm{mg} / \mathrm{kg}$ ) into Con A- or LPS-challenged mice showed similar effects, as the splenic lymphocyte proliferation decreased [114]. In addition, E. ulmoides has also been shown to have a therapeutic effect on autoimmune diseases such as RA, which has been discussed in the section on anti-inflammatory activities.

\section{Improving erectile activities of $E$. ulmoides}

Since 2005, it has been reported that E. ulmoides aqueous extract (10 and $100 \mu \mathrm{g} / \mathrm{ml}$ ) upregulated activity of SOD and $\alpha$-actin expression in the penile tissues of diabetic rats in vitro [115]. And In 2006, conducted in vivo, E. ulmoides aqueous extract $(400 \mathrm{mg} / \mathrm{kg})$ exhibited improving erectile function of diabetic rats via remitting the impairment of myelinated nerve fibers and enhancing the expression of nNOS in penile [116]. Recent years, Fu et al. performed a study to investigate how E. ulmoides exert therapeutic effects on erectile Dysfunction. E. ulmoides leaves aqueous extract $(0.5 \%, 1 \%$ and $2 \%$ of HFD) treated into streptozotocin-induced diabetic rats showed attenuating oxidative stress, increasing NO production, activating the Akt-eNOS pathway to restore endothelial function as well as enhancing hypothalamicpituitary-gonadal axis to improve erectile function [117].

\section{Anti-fatigue activities of E. ulmoides}

The seminal literature reporting on the anti-fatigue activities of E. ulmoides may conducted in 1999. It demonstrated that $E$. ulmoides leaves powder supplementation $(2.6 \mathrm{~g} / \mathrm{kg}$, consist $3 \%$ of diet) combination with mechanical training increased the ability to avoid lactate accumulation in skeletal muscle in rats, as characterized by improving 3-hydroxyacetyl-CoA dehydrogenase (HAD) and LDH activities. However, afterwards, this field of study was not explored in-depth [118].

\section{Anti-aging activities of E. ulmoides}

In 1999, a research reported that $E$. ulmoides leaves water soluble methanol extract treatment (mixed into $11 \%$ protein diet at $2.4 \%$ ), in false aged model rats, led to $20 \%$ significant higher turnover rate in the stratum corneum than the control value [119]. Subsequently, one of the iridoid mono-glycosides, namely geniposidic acid, which was an integral part of the extract, while administrated $(200 \mathrm{mg} /$ $\mathrm{kg}$ ) similarly caused a higher turnover rate at $23 \%$ in the stratum corneum. Aucubin was an anti-photo-induced aging compound, as it $(0.01,0.1$ and $1 \mu \mathrm{g} / \mathrm{ml})$ exhibited decreasing senescence-associated $\beta$-galactosidase (SA $\beta$-gal) activity in UVB-irradiated human skin fibroblast HS68 cells [120].

\section{Anti-fungal and anti-bacterial activities of E. ulmoides}

Modern studies have demonstrated the anti-fungal and anti-bacterial activities of E. ulmoides extracts. Typically, Zhang et al. tested the antifungal and antibacterial effects of E. ulmoides ethanol extract at three different concentrations $(0.01,0.10$ and $1.00 \mathrm{mg} / \mathrm{ml})$. The results showed E. ulmoides extract exhibit high inhibition activities against Aspergillus fumigatus fungus, Acinetobacter baumannii bacteria, Pseudomonas aeruginosa gram-negative and Staphylococcus aureus gram-positive bacteria [121].

\section{Novel components isolated from E. ulmoides and their biological activities}

As a particularly commonly utilized traditional Chinese medicine, E. ulmoides has long been one of the most popular drugs investigated. Over the past few decades, phytochemical investigations have demonstrated lignans, iridoids, phenolics, flavonoids, steroid and terpenoids as the main components present in E. ulmoides [6]. In the above section, the pharmacological activities of various extracts of the bark, leaves, and flowers of E. ulmoides as well as its various groups of active components have been discussed in detail. Herein, the chemical composition of lignans, iridoids, phenolic acids and flavonoids of E. ulmoides has been reorganized in Table 3 for reference based on the latest comprehensive review reports of $E$. ulmoides [122]. In addition, this section summarized the 
Table 3 Lignans, iridoids, phenolic acids and flavonoids from E. ulmoides bark, leaves, flowers, seed and root

\begin{tabular}{|c|c|c|c|c|}
\hline Medicine & Lignans & Iridoids & Phenolic acids & Flavonoids \\
\hline E. ulmoides bark & 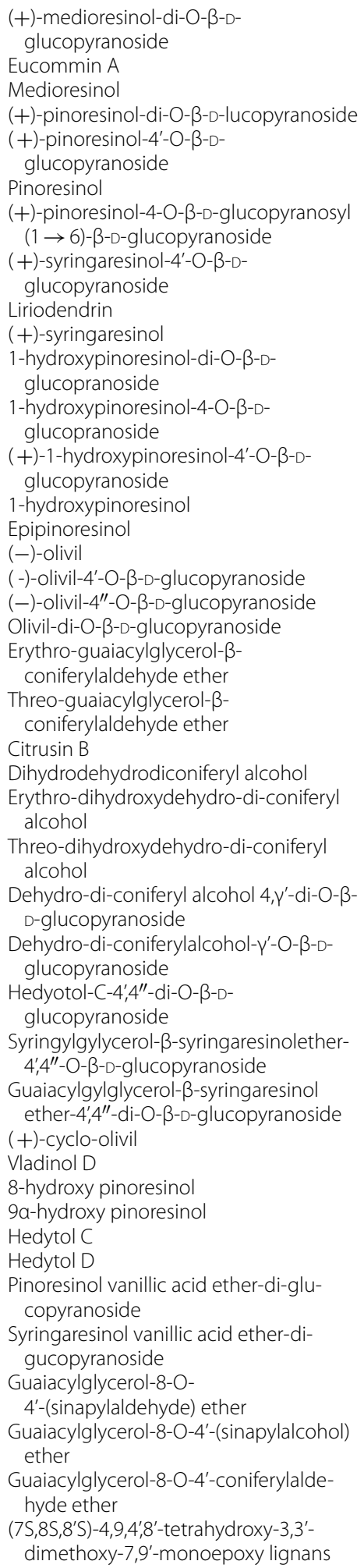 & $\begin{array}{l}\text { Geniposide } \\
\text { Geniposidic acid } \\
\text { Genipin } \\
\text { Eucommiol I } \\
\text { Eucommiol II } \\
\text { 1-deoxyeucommiol } \\
\text { Epieucommiol } \\
\text { Dihydrochalcone } \\
\text { Catalpol }\end{array}$ & $\begin{array}{l}\text { Vanillic acid } \\
\text { Ascorbic acid } \\
\text { Caffeic acid } \\
\text { Methyl chlorogenate } \\
\text { Chlorogenic acid } \\
\text { Coniferol } \\
\text { Eucophenoside } \\
\text { Erythro-guaiacylglycerol } \\
\text { Threo-guaiacylglycerol } \\
\text { Catechin } \\
\text { Epicatechin } \\
\text { Protocatechuic acid methyl } \\
\text { ester } \\
\text { 3-hydroxypropiovanllone } \\
\text { C-veratroylglycol } \\
\text { 3-hydroxy-4-methoxycinna- } \\
\text { maladehyde } \\
\text { Catechin-(7,8-b,c)-4a-(3,4- } \\
\text { dihyxyphenyl)-2(3H)- } \\
\text { pyranone } \\
\text { Catechin-(7,8-b,c)-43-(3,4- } \\
\text { dihyxyphenyl)-2(3H)- } \\
\text { pyranone } \\
\text { 3-hydroxy-1-(3-merhoxy- } \\
\text { 4-hydroxyphenyl)-pro- } \\
\text { pan-1-one } \\
\text { Licochalcone A }\end{array}$ & $\begin{array}{l}\text { Quercetin } \\
\text { Isoquercitrin (quercetin-3-o- } \\
\text { glucoside) } \\
\text { Quercetin-3-o-a-L- } \\
\text { glucopyranosyl } \\
\text { (1 } \rightarrow 2 \text { )- } \beta \text {-D- } \\
\text { glucopyranoside } \\
\text { Quercetin-3-o-xyloseglu- } \\
\text { coside (quercetin-3-O- } \\
\text { sambubioside) } \\
\text { Rutin } \\
\text { Hyperin (quercetin-3-o- } \\
\text { galactoside) } \\
\text { Kaempferol-3-o-glucoside } \\
\text { (astragalin) } \\
\text { Oroxylin } \\
\text { Wogonin } \\
\text { Wogonside } \\
\text { Isoliquiritigenin }\end{array}$ \\
\hline
\end{tabular}


Table 3 (continued)

\begin{tabular}{|c|c|c|c|c|}
\hline Medicine & Lignans & Iridoids & Phenolic acids & Flavonoids \\
\hline E. ulmoides leaves & $\begin{array}{l}\text { (+)-pinoresinol-di-O- } \beta \text {-D- } \\
\text { glucopyranoside } \\
\text { (-)-olivil-4'-O- } \beta \text {-D- } \\
\text { glucopyranoside } \\
\text { Lariciresinol } \\
\text { 8'-methoxy-olivil } \\
\text { 8-methoxy-medioresinol } \\
\text { 8-hydroxy-medioresinol }\end{array}$ & $\begin{array}{l}\text { Geniposidic acid } \\
\text { Aucubin } \\
\text { Ulmoidoside } \\
\text { Scandoside-10-o-acetate } \\
\text { Scandoside methylester } \\
\text { Deacetyl asperulosidic acid } \\
\text { methyl ester } \\
\text { Asperulosidic acid } \\
\text { Deacetyl asperuloside } \\
\text { Acid } \\
\text { Harpagide acetate } \\
\text { Reptoside } \\
\text { Eucommiol } \\
\text { Eucommiol I } \\
\text { Eucommiol II } \\
\text { 1-deoxyeucommiol } \\
\text { Epieucommiol } \\
\text { Asperuloside } \\
\text { Eucomosides A } \\
\text { Eucomosides B } \\
\text { Eucomosides C } \\
\text { Loganin } \\
\text { 7-epi-loganin } \\
\text { 8-epi-loganin }\end{array}$ & $\begin{array}{l}\text { Caffeic acid } \\
\text { Caffeic acid ethyl ester } \\
\text { Ferulic acid } \\
\text { P-coumaric acid } \\
\text { Methyl chlorogenate } \\
\text { Chlorogenic acid } \\
\text { 3-o-feruloylquinic acid } \\
\text { Catechin } \\
\text { Isochlorogenic acid a } \\
\text { Isochlorogenic acid c } \\
\text { Gallic acid } \\
\text { Protocatechuic acid } \\
\text { 3-(3,4-dihy-droxyphenyl) } \\
\text { propionic acid } \\
\text { 3-(3-hydroxyphenyl) propionic } \\
\text { acid } \\
\text { Pyrogallol } \\
\text { 5-methoxy-guaiacylglycerol } \\
\text { 5,9-dimethoxy-guaiacylg- } \\
\text { lycerol } \\
\text { 9-n-butyl-guaiacylglycerol } \\
\text { 9-n-butyl-isoguaiacylglycerol }\end{array}$ & $\begin{array}{l}\text { Isoquercitrin (quercetin-3-O- } \\
\text { glucoside) } \\
\text { Quercetin-3-O-a-L- } \\
\text { glucopyranosyl (1 } \rightarrow \text { 2)-B-D- } \\
\text { glucopyranoside } \\
\text { Quercetin-3-O-xyloseglucoside } \\
\text { (quercetin-3-O-sambubioside) } \\
\text { Rutin } \\
\text { Hyperin (quercetin-3-O-galac- } \\
\text { toside) } \\
\text { Quercetin 3-O-6"-acetyl- } \\
\text { glucopyranoside } \\
\text { Kaempferol-3-O-glucoside } \\
\text { (astragalin) } \\
\text { Kaempferol } \\
\text { Kaempherol 3-O-rutinoside } \\
\text { (nicotifiorin) } \\
\text { Kaempherol 3-O-sambubioside } \\
\text { Kaempferol 3-O-6"-acetyl- } \\
\text { Glucopyranoside } \\
\text { Baicalein } \\
\text { Luteolin }\end{array}$ \\
\hline E. ulmoides flowers & & $\begin{array}{l}\text { Asperulosidic acid } \\
\text { Ethyl ester } \\
\text { Daphylloside } \\
\text { 4-dihydro-3-methoxypaedero- } \\
\text { side }\end{array}$ & & 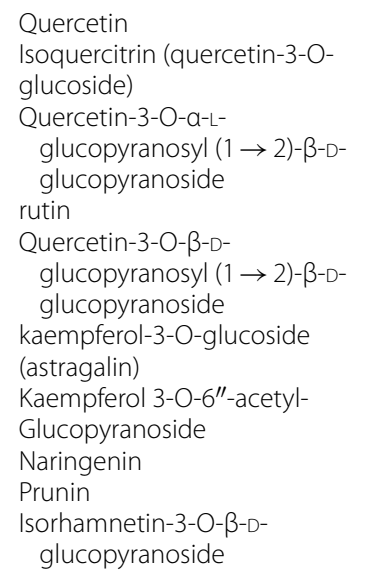 \\
\hline E. ulmoides seed & & $\begin{array}{l}\text { Geniposidic acid } \\
\text { Aucubin } \\
\text { Eucommiol II } \\
\text { Ulmoidoside A } \\
\text { Ulmoidoside B } \\
\text { Ulmoidoside C } \\
\text { Ulmoidoside D } \\
\text { Bartsioside } \\
\text { Ulmoidol A }\end{array}$ & $\begin{array}{l}\text { Caffeic acid } \\
\text { Chlorogenic acid } \\
\text { 3-(3,4-dihy-droxyphenyl) } \\
\text { propionic acid } \\
\text { Phthalic acid dibutyl ester } \\
\text { Phthalic acid bis-(7-ethy-2-hy- } \\
\text { droxyethyl decyl)-ester } \\
\text { Phthalic acid bis-(2-ethy } \\
\text { decyl)-ester }\end{array}$ & \\
\hline E. ulmoides root & & & Epigallocatechin & $\begin{array}{l}\text { Quercetin-3-O- } \beta \text {-D- } \\
\text { glucopyranosyl }(1 \rightarrow 2)-\beta \text {-D- } \\
\text { glucopyranoside } \\
\text { 4-methyl-7-hydroxycoumarin } \\
\text { procyanidin B2 } \\
\text { 4',7-dihydroxyflavene }\end{array}$ \\
\hline
\end{tabular}

novel components that have been isolated from E. ulmoides and their biological activities in the last two decades [123-129]. As showed in Figure 3, three monoterpenes (compounds 1, 2 and 3), a triterpene (compounds 4), seven iridoids (compounds 5, 7, 8, 9, 10, 11 and 13), two lignans (compounds 12 and 14), four phenolics (compounds 15, 16, 17, 18) and an ester (compound 6) were isolated from $E$. ulmoides. 
<smiles>O=C1C[C@@H]2CCC=C(CO)[C@@]2(CO)O1</smiles>

1<smiles>CCCCO[C@H](c1ccc(O)c(OC)c1)[C@H](CO)c1ccc(O)c(OC)c1</smiles>

15<smiles>CC1=CC(=O)CC(C)(C)[C@H]1CCC(C)C</smiles>

2<smiles>O=C(O)CO</smiles><smiles>OC1CCC1</smiles><smiles>COC1C[C@H](O)C[C@@H](O)[C@H]1O</smiles><smiles>CC(=O)[C@H]1OC=C(C(=O)N[C@@H](Cc2c[nH]c3ccccc23)C(=O)O)[C@@]2(C)C(CO)=CC[C@@H]12</smiles>

3<smiles>CC1=CC(=O)CC(C)(C)[C@H]1CCC(C)C</smiles>

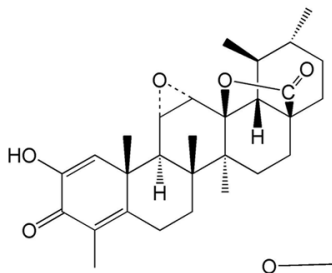<smiles>CCCCCOCC=CCOC(C)=O</smiles>

7

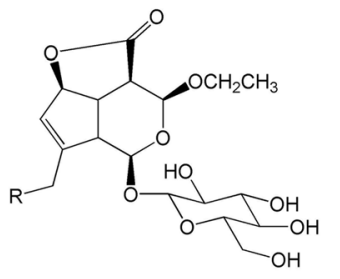

$10 \mathrm{R}=\mathrm{OAC}$ $11 \mathrm{R}=\mathrm{OH}$<smiles>CCCCO[C@H](c1ccc(O)c(OC)c1)[C@@H](CO)c1ccc(O)c(OC)c1</smiles>

16<smiles>C=C(/C=C/O)C(c1ccc(O)c(OC)c1)C1COC(=O)C1</smiles>

12<smiles>CCCCO[C@H](c1ccc(O)c(OC)c1)[C@@H](CO)c1ccc(O)c(OC)c1</smiles>

17<smiles>CO[C@@H]1CC2C=C[C@@]3(O)CO[C@H](O1)C23</smiles>

5

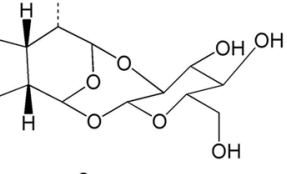<smiles>COc1cc([C@H]2c3cc(O)c(OC)cc3C[C@](O)(CO)[C@H]2CO)ccc1O</smiles><smiles>CO[C@H]1CC2C(C(C)=C[C@H]2O)[C@H](OC)O1</smiles>

13<smiles>CCCCO[C@H](c1ccc(O)c(OC)c1)[C@@H](CO)c1ccc(O)c(OC)c1</smiles>

Fig. 3 Novel components isolated from E. ulmoides in the last twenty years (2000 - 2020)

Compound 1 was a monoterpene isolated from $E$. ulmoides bark [125]. Compounds 2 and 3 were a pair of megastigmane enantiomers isolated from E. ulmoides leaves[128]. Docking-based virtual screening of both compounds showed weak intermolecular interactions with the binding site residues of angiotensin-converting enzyme [130] and angiotensin II type 1 receptor $\left(\mathrm{AT}_{1} \mathrm{R}\right)$. Cytotoxic activity was tested for the compound against K562 and HepG2 cells and the result indicated no anticancer activity. Compound $\mathbf{4}$ was a ursane-type nortriterpenoid isolated from E. ulmoides leaves and the trails showed no inhibition to proteintyrosine phosphatase-1B (PTP1B) activities [127]. Compounds 8, 9 and 7 were iridoids isolated from $E$. ulmoides leaves, termed eucomosides A-C [123]. Compounds 5, 10, 11, 13 were iridoids as well but isolated from E. ulmoides male flowers and the trails showed no significant promoting proliferation effects on skin fibroblasts cell (ESF-1) [124]. Compounds 12 and 14 were lignans isolated from E. ulmoides bark [126]. The neuroprotective activity of both compounds against glutamate-induced HT-22 cells injury was evaluated, and only compound $\mathbf{1 2}$ exhibited moderate effect at the concentrations ranging from 10 to $50 \mu \mathrm{M}$. Compounds $15,16,17,18$ were two pairs of new phenolic enantiomers isolated from E. ulmoides leaves[129], but no compounds showed potential cytotoxic activities against Hep G2 in vitro. Compound $\mathbf{6}$ was a quinic acid diester isolated from $E$. ulmoides leaves, termed eucommicin $\mathrm{A}$. The $\mathrm{IC}_{50}$ of eucommicin A was $55.0 \mu \mathrm{M}$ reduced the viability of iCSCL-10A cells [113]. 
In addition to low-molecular components, there were also several high-molecular components isolated from E. ulmoides been reported. In 2016, three novel polysaccharides were isolated and purified from E. ulmoides, termed, EUP1, EUP2 and EUP3. Among them, EUP3 has been discovered as the first nonglycosaminoglycan, nonanimal-originated carbohydrate molecule that binds (10 or $100 \mu \mathrm{g} / \mathrm{mL}$ ) two pro-angiogenic growth factors, namely, fibroblast growth factor-2 (FGF-2) and platelet-derived growth factor-BB (PDGF$\mathrm{BB})$, to stimulate angiogenesis [131]. Subsequently, the team designed and fabricated a novel engineered biomaterial, electrospun hydrogel sponge (EGC), based on EUP3 and gelatin to mimic ECM to activate endogenous tissue repair. Animal experiments showed that EGS accelerated the repair of a full-thickness skin wound in mice and induced optimal neo-tissue formation, without the addition of any exogenous GFs, cells or genes [132]. In 2019, the biological applications of EUP3 are being further explored. This study presents a microcarrier system, combining PDGF-BB and PDGFBB-binding EUP3 for mesenchymal stem cell (MSC) cultivation, which play a role in cell-based therapy strategy towards various diseases and tissue injury [133]. Except for EUP3, EUP1, a novel polysaccharide isolated from E. ulmoides, both in vivo and in vitro trails have demonstrated its anti-inflammatory activities. In LPSchallenged Raw 264.7 cells, EUP1 (10, 25 and $50 \mu \mathrm{g} / \mathrm{ml})$ reduced the expression of TNF- $\alpha$ in a dose dependent manner. In LPS-induced sepsis mice, EUP1 $(10 \mathrm{mg} / \mathrm{kg})$ reserved the upregulation of TNF- $\alpha$, IL-1 $\beta$ and IL- 6 levels in lung tissue [134]. In a study reported in 2004 [135], a novel flavonol glycoside was identified $\mathrm{IC}_{50}$ at $2.95 \times 10^{-7} \mathrm{M}$ in inhibition test on protein glycation in vitro. Besides, four new megastigmane glycosides isolated from $E$. ulmoides leaves, termed eucomegastigsides A-D, were found inhibition ratios of $24.6 \pm 0.5 \%$, $29.1 \pm 0.6 \%, 31.2 \pm 0.2 \%$ and $29.7 \pm 0.4 \%$ respectively at the concentration of $240 \mu \mathrm{g} / \mathrm{mL}$ against angiotensin converting enzyme [130], which were correlative with the anti-hypertensive activities, and showing moderate activities compared with captopril $(98.0 \pm 0.1 \%$ at 240 $\mu \mathrm{g} / \mathrm{mL})[136]$.

As the second natural rubber resource and one of the main components, E. ulmoides rubber, it is worth mentioning that although $E$. ulmoides rubber is not a novel isolated and discovered compound, in the past few years, the great potential application of E. ulmoides rubber has received increasing attention in the fields of the environment, agriculture, engineering, and biomedical engineering etc. Very recently, a comprehensive review summarized the novel applications of E. ulmoides in diverse fields [137].

\section{Current developments and limitations of $E$. ulmoides}

As described in present review, E. ulmoides has been proved to possess a variety of pharmacological activities (Fig. 4). Compared with its recommended therapeutic usages recorded in ancient Chinese medical textbooks, there are still several traditional usages are not estimated by modern pharmacological research, involving intestinal haemorrhoids, vaginal bleeding, dampness and residual draining of urine, abortion, pregnancy bleeding et al. Further investigations are still needed to fully reveal the potential clinical application of E. ulmoides and the following aspects are worth addressing.

Firstly, as can be seen in Table 2, there are significant differences in the total phenolics, total flavonoids and other active compounds contents of the seed, leaves and bark of E. ulmoides. It is clear that inconsistent chemical composition determines the differences in pharmacological activities. The modern Chinese Pharmacopoeia involving both the bark and the leaves of E. ulmoides. However, a variety of studies utilizing the medicinal parts of E. ulmoides includes bark, leaves, seed and even male flowers, diversely. Sometimes they are applied as alternative medicines to each other, as they exhibit relatively consistent pharmacological activities and biological mechanisms under certain physiopathological conditions. Overall, both specificities and similarities present in different medicinal parts of E. ulmoides. Nevertheless, there is still a lack of systematic investigation unveiling a comprehensive account of the differences in the various components and pharmacological activities of the distinct medicinal parts of E. ulmoides.

Secondly, in Wu Yiluo's "New Compilation of Material Medica", a decoction of E. ulmoides in a 50/50 ratio of wine and water is recorded. The preparation of $E$. ulmoides bark in the Pharmacopoeia is based on reflux extraction with trichloromethane, followed by discarding the trichloromethane solution and refluxing the residue with methanol in water to obtain the extract. In the Pharmacopoeia, the preparation of E. ulmoides leaves is done by reflux extraction with $50 \%$ methanol. However, for decades, the solvents used for the preparation of extracts from E. ulmoides have involved distilled water, methanolic water and ethanolic water. The results obtained from studies of extracts prepared by different processes will not be comparable with each other. In addition, the ultimate efficacy of a drug is influenced by multiple factors other than the preparation process, including planting conditions of soil, geographical location, fertilization methods, harvesting season, etc. For example, it has been shown that harvesting the leaves of E. ulmoides in May or August guarantees the best antioxidant activity [57]. In a nutshell. 


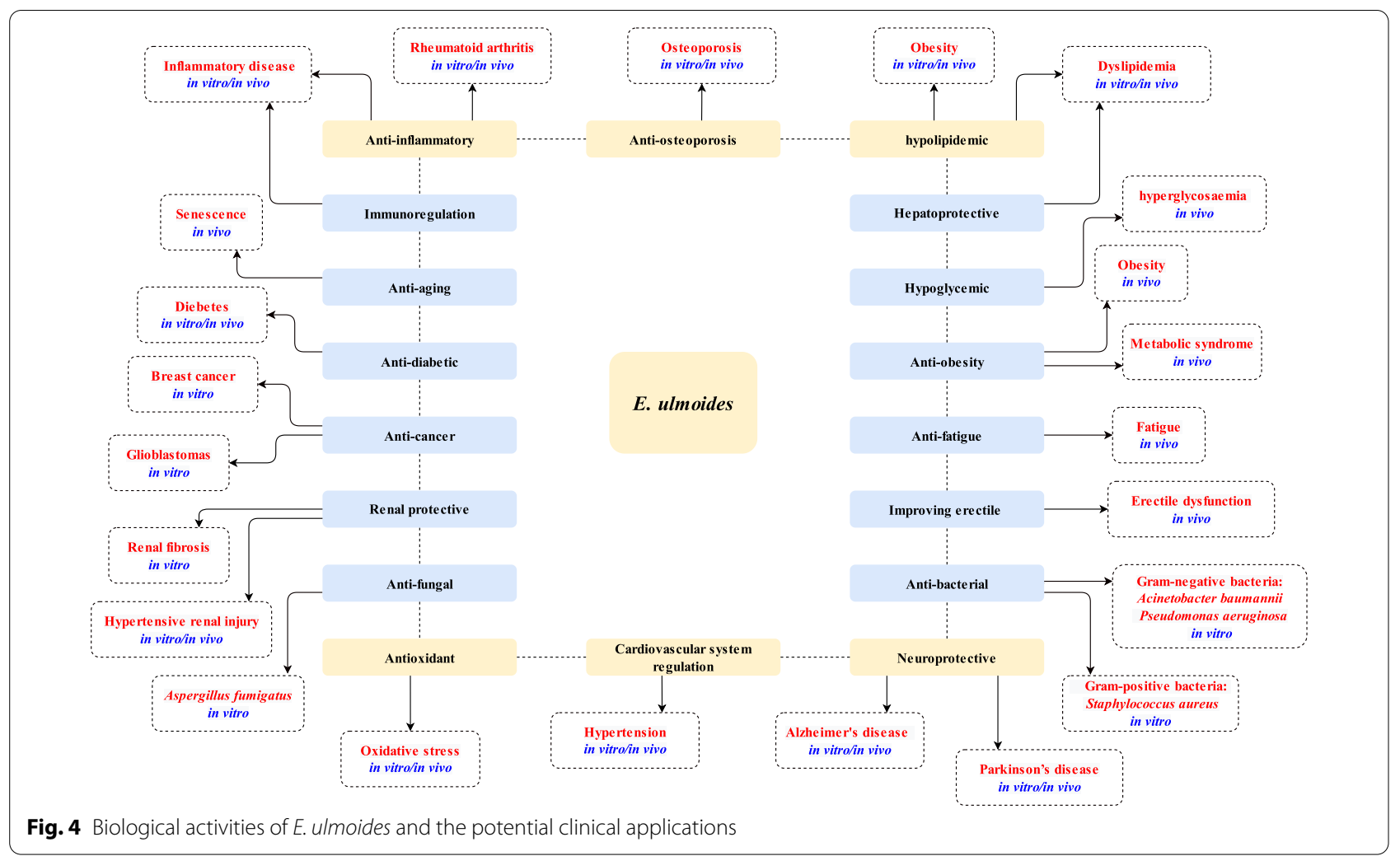

clarification of the chemical profiles and development of standard operating procedures for the E. ulmoides products will be crucial in further research.

Thirdly, research on the pharmacological activities of E. ulmoides, including anti-cancer, anti-fungal and bacterial, anti-fatigue, anti-ageing, hypoglycaemic and immunomodulatory, is still in its infancy. Studies on the anti-cancer activities of E. ulmoides only remain at the stage of in vitro trails. Studies on the anti-fungal and anti-bacterial activities of E. ulmoides are also limited to in vitro trails and lack systematic studies to fully reveal its anti-bacterial and anti-fungal spectrum. In vivo tests have demonstrated the anti-fatigue effects of E. ulmoides, but the biological mechanism is not yet known. Similarly, while both in vivo and in vitro tests have demonstrated the anti-ageing effects of E. ulmoides, but the mechanism of action needs to be elucidated. It is known that E. ulmoides exhibits increasing plasma insulin levels, but this merely results in a small decrease in blood glucose level in diabetic models, and the mechanism of its effect is still unknown. As discussed above, it has been demonstrated that $E$. ulmoides has a lymphoproliferative effect and hence enhances the immune function of the body, however, the mechanism of its effect has not yet been elucidated and its immunomodulatory effect needs to be further explored. In addition, overall, there is a lack of clinical trials on the effectiveness of the various pharmacological activities of $E$. ulmoides.

Fourthly, synergistic effects have been demonstrated between the various compounds inherent in the treatment with $E$. ulmoides, and the interactions may be more complex than thought. For instances, the methanolic extract of E. ulmoides has a much stronger effect on collagen synthesis than the acetone fraction of $E$. ulmoides at similar doses. Interestingly, the rest of the n-butanol fraction, the ethyl acetate fraction and the remaining methanol fraction after fractionation were not found to promote collagen synthesis [28]. Thus, there are complex biological mechanisms underlying the in vivo conditions of $E$. ulmoides extracts that are not yet known. On the other hand, in vivo experiments reported in 2010 showed no hypotensive effect of the iridoids components of $E$. ulmoides, however, several iridoids components isolated from E. ulmoides summarized in a 2014 review showed some hypotensive activities in either in vivo or in vitro experiments $[6,7]$. It seemed contradictory, yet it may occur owing to the possible interaction among the multiple components when they are present together in vivo, leading to their ineffectiveness. The in vivo interaction pattern of multiple components of botanicals remains a major blind spot in this field of research. The synergistic effects $E$. ulmoides in vivo are likewise of great interest. 
Fifthly, it is believed that the pharmacological activities of $E$. ulmoides is attributed to diverse chemical components. Indeed, the chemical components isolated from E. ulmoides exhibit similar effects to those of E. ulmoides extract in numerous pathological contexts. Representatively, a large body of studies have demonstrated the potential biological activities of aucubin involving hypotensive, anti-osteoporotic, antioxidant, hypolipidemic and neuroprotective. In addition, geniposide, geniposidic acid and chlorogenic acid isolated from $E$. ulmoides have also demonstrated multiple pharmacological activities. Although clinical studies are still needed to further establish the effectiveness of these components, it is merit investigation as potential therapeutics.

In addition to the numerous pharmacological studies, E. ulmoides had also been widely investigated in other aspects. Above all, iridoids are one of the main active components of $E$. ulmoides. Among them, geniposide and its aglucone genipin by which biological mechanism exerting anti-cancer activities has been discussed in-depth [2, 138-141]. Besides, other pharmacological activities of geniposide have been covered by a large body of excellent reviews. Next, pharmacokinetic investigation, optimization of extraction methods and toxicological trails have also been carried out on E. ulmoides [142-147].

\section{Summary}

In summary, extensive in vitro and in vivo data have revealed that $E$. ulmoides possess multiple excellent biological activities, including cardiovascular system regulation, anti-osteoporotic, anti-inflammatory, antioxidant, hypolipidemic, neuroprotective, hypoglycemic, anti-obesity, anti-diabetic, hepatoprotective and renal protective, anti-cancer, immunoregulation, improving erectile, antifatigue, anti-aging, anti-fungal, anti-bacterial, supporting the promising therapeutic application of E. ulmoides in various human diseases. For the next decade, more clinical indications would be found with more pharmacological mechanism of E. ulmoides being unveiled. We hope this review could provide a scientific basis for further investigations to assess mechanism underlying the effects and clinical applications of E. ulmoides.

\footnotetext{
Abbreviations

8-OHdG: 8-Hydroxy-2 deoxyguanosine; ACAT: CoA: cholesterol acyltransferase; ACE2: Angiotensin-converting enzyme 2; AChE: Acetyl-cholinesterase; ACOEt: Ethyl acetate; AEEuL: Aqueous extract of E. ulmoides leaf; AEF-MEEuL: AcOEt fraction of the methanol extract of leaf; AF-MEEuC: Aqueous fraction of the methanol extract of cortex; AF-MEEuL: Acetone fraction of the methanol extract of leaf; AGEs: Advanced glycation end-products; Akt: Protein kinase B; AMPK: Adenosine 5'-monophosphate (AMP)-activated protein kinase; Ang II: Angiotensin II; Ang-(1-7): Angiotensin-(1-7); AR: Aldose reductase; AT1R: Angiotensin II type 1 receptor; ATP: Adenosine triphosphate; A $\beta$ : Amyloid- $\beta$ peptide; BAT-SNA: Brown adipose tissue sympathetic nerve activity; $\mathrm{BCl}-2$ : B-cell
}

lymphoma-2; BF-MEEuC: Butanol fraction of the methanol extract of cortex; BMP-2: Bone morphogenetic protein-2; BrdU: 5-Bromo-2-deoxyUridine; CAMP: Cyclic adenosine monophosphate; CAT: Catalase; CIA: Collagen-induced arthritis; Con A: Concanavalin A; COX-2: Cyclooxygenase-2; CSCs: Cancer stem cells; CTGF: Connective tissue growth factor; DNA: DeoxyriboNucleic acid; DPPH: 1,1-Diphenyl-2-picrylhydrazyl; E. ulmoides: Eucommia ulmoides Oliv.; EC50: Concentration for $50 \%$ of maximal effect; EEEuL: Ethanol extract of E. ulmoides leaf; EEEURB: Ethanol extract of E. ulmoides roasted bark; EEEUS: Ethanol extract of E. ulmoides seed; EF-MEE: Ethylacetate fraction of the methanol extract of cortex; eNOS: Endothelial nitric oxide synthase; ERK1/2: Extracellular signalregulated kinase 1/2; GH: Growth hormone; GPH-Px: GSH peroxidase; GR: GSH reductase; GRF: Growth hormone releasing factors; GSH: Glutathione; GSK-3 $\beta$ : Glycogen synthase kinase-3ß; GST: GSH S-transferase; GVNA: Gastric vagal nerve activity; HAD: 3-Hydroxyacetyl-CoA dehydrogenase; HbA1c: Glycated hemoglobin; HDLC: High-density lipoprotein cholesterol; HFD: High-fat diet; HLS: Hind limb suspension; HMGB1: High mobility group protein; HMG-CoA: 3-Hydroxy-3-methylglutaryl CoA; HO-1: Heme oxygenase-1; I/R: Ischemia/ reperfusion; IC50: 50\% Inhibiting concentration; iCSCL: Induced CSC-like; IFN: Interferon; IGF-1: Insulin-like growth factors-1; IL: Interleukin; iNOS: Inducible nitric oxide synthase; IKB: Inhibitor of NF-KB; JNK: C-JunN-terminalkinase; LDH: Lactate dehydrogenase; LPS: Lipopolysaccharide; MAPK: Mitogen-activated protein kinase; MDA: Malondialdehyde; MEEUC: Methanol extract of E. ulmoides cortex; MEEuL: Methanol extract of E. ulmoides leaf; MF-MEEuL: Methonal fraction of the methanol extract of leaf; MGO: Methylglyoxal; MMP-2: Matrix Metallopeptidase 2; MMP-9: Matrix metallopeptidase 9; MPTP: 1-Methyl-4-phenyl-1,2,3,6-tetrahydropyridine; mTOR: Mammalian target of rapamycin; Myd88: Myeloiddifferentiationfactor 88; NAFLD: Non-alcoholic fatty liver disease; NAG: $N$-Acetyl- $\beta$-D-glucosaminidase; NF-MEEuL: N-hexane fraction of the methanol extract of leaf; NF-kB: Nuclear factor kappa-B; NLRP3: Nod-like receptor protein 3; nNOS: Neuronal nitric oxide synthase; NO: Nitric oxide; Nrf2: Nuclear factor E2-related factor 2; OHDA: 6-Hydroxydopamine-induced; OPG: Osteoprotegerin; OVX: Ovariectomy; PAMPs: Pathogen-associated molecular patterns; PARP: Poly-ADP-ribosepolymerase; PAS: Periodic acid-Schiff; PG: (+)-Pinoresinol di- $\beta$-D-glucoside; PI3K: Phosphatidylinositol 3-kinase; PILO: Pilocarpine; P-IKB: Phospho-IkB; P-p65: Phospho-p65; PTP1B: Proteintyrosine phosphatase1B; RA: Rheumatoid arthritis; RANKL: Receptor activator of nuclear factor-kB ligand; RMCs: Renal mesangial cells; ROS: Reactive oxygen species; SA $\beta$-gal: Senescence-associated $\beta$-galactosidase; SHRs: Spontaneously hypertensive rats; Sirt1: Sirtuin; SMC: Smooth muscle cell; SOD: Superoxide dismutase; SPF: Specific-pathogen-free; ssDNA: Single-stranded DNA; STAT: Signal transducer and activator of transcription; TBARS: Thiobarubiturate reactive substances; TGF- $\beta$ : Transforming growth factor- $\beta$; Th17: T helper cell 17; TLR4: Toll-like receptors 4; TNF-a: Tumor necrosis factor-a; TUNEL: TdT-mediated dUTP-biotin nick end labeling; UCP1: Uncoupling protein 1; UPS: Ubiquitin-proteasome system; VC: Vitamin C; WAT-SNA: White adipose tissue sympathetic nerve activity; $\beta 3-A R$ : $\beta 3$-Adrenergic receptor.

\section{Acknowledgements}

Not applicable.

\section{Authors' contributions}

GC organized, conceived, and supervised the study. LH, QL drafted the manuscript. WZ and QY revised the manuscript. All authors read and approved the final manuscript.

\section{Funding}

This work was financially supported by the National Natural Science Foundation of China (Nos. 81973481 and 81922073), and the Traditional Chinese Medicine Key Scientific Research Fund Project of Zhejiang Province (Nos. Q2019J02 and 2021ZZ009). Program of China (No. 2017YFE0191500).

\section{Availability of data and materials}

Not applicable.

\section{Declarations}

Ethics approval and consent to participate Not applicable. 


\section{Consent for publication \\ Not applicable.}

\section{Competing interests}

The authors declare that they have no competing interests.

Received: 24 May 2021 Accepted: 29 July 2021

Published online: 06 August 2021

\section{References}

1. Liu PF, Wang L, Du QX. Estimation of potential suitable distribution area and the ecological characteristics of Eucommia ulmoides Oliv. in China. Acta Ecol Sin. 2020;98:5674-84.

2. Habtemariam S, Lentini G. Plant-derived anticancer agents: lessons from the pharmacology of geniposide and its aglycone genipin. Biomedicines. 2018;6:2

3. Zeng X, Guo F, Ouyang D. A review of the pharmacology and toxicology of aucubin. Fitoterapia. 2020;140:104443.

4. Sih CJ, Ravikumar PR, Huang FC, Buckner C, Whitlock H Jr. Isolation and synthesis of pinoresinol diglucoside, a major antihypertensive principle of Tu-Chung (Eucommia ulmoides, Oliver). J Am Chem Soc. 1976:98(17):5412-3.

5. Shchepotin BM, Shchulipenko IM. Treatment of patients with hypertension with an extract of the leaves of Eucommia ulmoides. Vrach Delo. 1983;1:30.

6. He X, Wang J, Li M, Hao D, Yang Y, Zhang C, He R, Tao R. Eucommia ulmoides Oliv:: ethnopharmacology, phytochemistry and pharmacology of an important traditional Chinese medicine. J Ethnopharmacol. 2014;151(1):78-92.

7. Luo LF, Wu WH, Zhou YJ, Yan J, Yang GP, Ouyang DS. Antihypertensive effect of Eucommia ulmoides Oliv. extracts in spontaneously hypertensive rats. J Ethnopharmacol. 2010;129(2):238-43.

8. Gu J, Wang JJ, Yan J, Cui CF, Wu WH, Li L, Wang ZS, Yu M, Gao N, Liu L, et al. Effects of lignans extracted from Eucommia ulmoides and aldose reductase inhibitor epalrestat on hypertensive vascular remodeling. J Ethnopharmacol. 2011;133(1):6-13.

9. Li L, Yan J, Hu K, Gu J, Wang JJ, Deng XL, Li H, Jing X, Li ZY, Ye QF, et al. Protective effects of Eucommia lignans against hypertensive renal injury by inhibiting expression of aldose reductase. J Ethnopharmacol. 2012;139(2):454-61.

10. Li ZY, Gu J, Yan J, Wang JJ, Huang WH, Tan ZR, Zhou G, Chen Y, Zhou HH, Ouyang DS. Hypertensive cardiac remodeling effects of lignan extracts from Eucommia ulmoides Oliv. bark-a famous traditional Chinese medicine. Am J Chin Med. 2013;41(4):801-15

11. Ding ZJ, Liang C, Wang X, Yao X, Yang RH, Zhang ZS, He JJ, Du HY, Fang D, Li Q. Antihypertensive activity of Eucommia Ulmoides Oliv.: male flower extract in spontaneously hypertensive Rats. Evid Based Complement Alternat Med. 2020;2020:6432173.

12. Ramasamy R, Goldberg IJ. Aldose reductase and cardiovascular diseases, creating human-like diabetic complications in an experimental model. Circ Res. 2010;106(9):1449-58.

13. Duan M, Yuan Y, Liu C, Cai Z, Xie Q, Hu T, Tang Q, Wu Q. Indigo fruits ingredient, aucubin, protects against LPS-induced cardiac dysfunction in mice. J Pharmacol Exp Ther. 2019;371(2):348-59.

14. Li N, Zhou H, Ma ZG, Zhu JX, Liu C, Song P, Kong CY, Wu HM, Deng W, Tang QZ. Geniposide alleviates isoproterenol-induced cardiac fibrosis partially via SIRT1 activation in vivo and in vitro. Front Pharmacol. 2018;9:854.

15. Ma ZG, Dai J, Zhang WB, Yuan Y, Liao HH, Zhang N, Bian ZY, Tang QZ. Protection against cardiac hypertrophy by geniposide involves the GLP-1 receptor / AMPKalpha signalling pathway. Br J Pharmacol. 2016;173(9):1502-16.

16. Ma ZG, Kong CY, Song P, Zhang X, Yuan YP, Tang QZ. Geniposide protects against obesity-related cardiac injury through AMPKalpha- and Sirt1-dependent mechanisms. Oxid Med Cell Longev. 2018:2018:6053727.

17. Meng YY, Yuan YP, Zhang X, Kong CY, Song P, Ma ZG, Tang QZ. Protection against Doxorubicin-Induced Cytotoxicity by Geniposide
Involves AMPKalpha Signaling Pathway. Oxid Med Cell Longev. 2019;2019:7901735.

18. Sheng C, Hu F, Wu L. Geniposide alleviates hypoxia-induced injury by down-regulation of IncRNA THRIL in rat cardiomyocytes derived H9c2 cells. Eur J Pharmacol. 2019:854:28-38.

19. Wu QQ, Xiao Y, Duan MX, Yuan Y, Jiang XH, Yang Z, Liao HH, Deng W, Tang QZ. Aucubin protects against pressure overload-induced cardiac remodelling via the beta3 -adrenoceptor-neuronal NOS cascades. $\mathrm{Br} J$ Pharmacol. 2018;175(9):1548-66.

20. Xiao Y, Chang W, Wu Q, Jiang X, Duan M, Jin Y, Tang QJP. Aucubin Protects against TGF $\beta 1$-Induced Cardiac Fibroblasts Activation by Mediating the AMPKa/mTOR Signaling Pathway. Planta Med. 2018;84(2):91-9.

21. Yang Z, Wu QQ, Xiao Y, Duan MX, Liu C, Yuan Y, Meng YY, Liao HH, Tang QZ. Aucubin protects against myocardial infarction-induced cardiac remodeling via nNOS/NO-regulated oxidative stress. Oxid Med Cell Longev. 2018;2018:4327901.

22. Pan Y, Niu Y, Li C, Zhai Y, Zhang R, Guo X, Mei Q. Du-zhong (Eucommia ulmoides) prevents disuse-induced osteoporosis in hind limb suspension rats. Am J Chin Med. 2014;42(1):143-55.

23. Qi S, Zheng $\mathrm{H}$, Chen $\mathrm{C}$, Jiang $\mathrm{H}$. Du-Zhong (Eucommia ulmoides Oliv.) cortex extract alleviates lead acetate-induced bone loss in rats. Biol Trace Elem Res. 2019;187(1):172-80.

24. Zhang R, Liu ZG, Li C, Hu SJ, Liu L, Wang JP, Mei QB. Du-Zhong (Eucommia ulmoides Oliv.) cortex extract prevent OVX-induced osteoporosis in rats. Bone. 2009;45(3):553-9.

25. Zhang R, Pan YL, Hu SJ, Kong XH, Juan W, Mei QB. Effects of total lignans from Eucommia ulmoides barks prevent bone loss in vivo and in vitro. J Ethnopharmacol. 2014;155(1):104-12.

26. Zhang W, Fujikawa T, Mizuno K, Ishida T, Ooi K, Hirata T, Wada A. Eucommia leaf extract (ELE) prevents OVX-induced osteoporosis and obesity in rats. Am J Chin Med. 2012;40(4):735-52.

27. Zhao X, Wang Y, Nie Z, Han L, Zhong X, Yan X, Gao X. Eucommia ulmoides leaf extract alters gut microbiota composition, enhances short-chain fatty acids production, and ameliorates osteoporosis in the senescence-accelerated mouse P6 (SAMP6) model. Food Sci Nutr. 2020;8(9):4897-906

28. Li Y, Sato T, Metori K, Koike K, Che QM, Takahashi S. The promoting effects of geniposidic acid and aucubin in Eucommia ulmoides Oliver leaves on collagen synthesis. Biol Pharm Bull. 1998;21(12):1306-10.

29. Marini JC, Forlino A, Bachinger HP, Bishop NJ, Byers PH, Paepe A, Fassier F, Fratzl-Zelman N, Kozloff KM, Krakow D, et al. Osteogenesis imperfecta. Nat Rev Dis Primers. 2017:3:17052.

30. $\mathrm{Ha} \mathrm{H}, \mathrm{Ho}$ J, Shin S, Kim H, Koo S, Kim IH, Kim C. Effects of Eucommiae Cortex on osteoblast-like cell proliferation and osteoclast inhibition. Arch Pharm Res. 2003;26(11):929-36

31. Kim JY, Lee Jl, Song M, Lee D, Song J, Kim SY, Park J, Choi HY, Kim H. Effects of Eucommia ulmoides extract on longitudinal bone growth rate in adolescent female rats. Phytother Res. 2015;29(1):148-53.

32. Li Y, Wang MJ, Li S, Zhang YM, Zhao Y, Xie RM, Sun WJ. Effect of total glycosides from Eucommia ulmoides seed on bone microarchitecture in rats. Phytother Res. 2011:25(12):1895-7.

33. Koh W, Shin JS, Lee J, Lee IH, Lee SK, Ha IH, Chung HJ. Anti-inflammatory effect of Cortex Eucommiae via modulation of the toll-like receptor 4 pathway in lipopolysaccharide-stimulated RAW 264.7 macrophages. J Ethnopharmacol. 2017:209:255-63.

34. Kwon SH, Ma SX, Hwang JY, Ko YH, Seo JY, Lee BR, Lee SY, Jang CG. The anti-inflammatory activity of Eucommia ulmoides Oliv. Bark. Involves NF-kappaB Suppression and Nrf2-Dependent HO-1 Induction in BV-2 Microglial Cells. Biomol Ther (Seoul). 2016;24(3):268-82.

35. Wang JY, Chen XJ, Zhang L, Pan YY, Gu ZX, He SM, Song ZP, Yuan Y. Comparative studies of different extracts from Eucommia ulmoides Oliv. against rheumatoid arthritis in CIA rats. Evid Based Complement Alternat Med. 2018;2018:7379893.

36. Wang JY, Chen XJ, Zhang L, Pan YY, Gu ZX, Yuan Y. Anti-inflammatory effects of Eucommia ulmoides Oliv. male flower extract on lipopolysaccharide-induced inflammation. Chin Med J (Engl). 2019;132(3):319-28.

37. Wang JY, Yuan Y, Chen XJ, Fu SG, Zhang L, Hong YL, You SF, Yang YQ. Extract from Eucommia ulmoides Oliv. ameliorates arthritis via regulation of inflammation, synoviocyte proliferation and osteoclastogenesis in vitro and in vivo. J Ethnopharmacol. 2016;194:609-16. 
38. Chen Y, Pan R, Zhang J, Liang T, Guo J, Sun T, Fu X, Wang L, Zhang L. Pinoresinol diglucoside (PDG) attenuates cardiac hypertrophy via AKT/ mTOR/NF-KB signaling in pressure overload-induced rats. J Ethnopharmacol. 2021;23(272):113920.

39. Chen S, Zeng X, Zong W, Wang X, Chen L, Zhou L, Li C, Huang Q, Huang $X$, Zeng $G$, et al. Aucubin alleviates seizures activity in li-pilocarpineinduced epileptic mice: involvement of inhibition of neuroinflammation and regulation of neurotransmission. Neurochem Res. 2019:44(2):472-84.

40. Zhu YL, Sun MF, Jia XB, Zhang PH, Xu YD, Zhou ZL, Xu ZH, Cui C, Chen $X$, Yang XS, et al. Aucubin alleviates glial cell activation and preserves dopaminergic neurons in 1-methyl-4-phenyl-1,2,3,6-tetrahydropyridine-induced parkinsonian mice. NeuroReport. 2018;29(13):1075-83.

41. Kim MC, Kim DS, Kim SJ, Park J, Kim HL, Kim SY, Ahn KS, Jang HJ, Lee SG, Lee KM, et al. Eucommiae cortex inhibits TNF-alpha and IL-6 through the suppression of caspase-1 in lipopolysaccharide-stimulated mouse peritoneal macrophages. Am J Chin Med. 2012;40(1):135-49.

42. Cuzzocrea S, Riley DP, Caputi AP, Salvemini D. Antioxidant therapy: a new pharmacological approach in shock, inflammation, and ischemia/ reperfusion injury. Pharmacol Rev. 2001;53(1):135-59.

43. Fitzgerald KA, Kagan JC. Toll-like Receptors and the Control of Immunity. Cell. 2020;180(6):1044-66.

44. Hussain T, Yuan D, Tan B, Murtaza G, Rahu N, Kalhoro MS, Kalhoro DH, Yin Y. Eucommia ulmoides flavones (EUF) abrogated enterocyte damage induced by LPS involved in NF-kappaB signaling pathway. Toxicol In Vitro. 2020;62:104674

45. Gao W, Feng Z, Zhang S, Wu B, Geng X, Fan G, Duan Y, Li K, Liu K, Peng C. Anti-Inflammatory and Antioxidant Effect of Eucommia ulmoides Polysaccharide in Hepatic Ischemia-Reperfusion Injury by Regulating ROS and the TLR-4-NF-kappaB Pathway. Biomed Res Int. 2020;2020:1860637.

46. Taams LS. Interleukin-17 in rheumatoid arthritis: Trials and tribulations. J Exp Med. 2020;217:3.

47. Takeuchi Y, Hirota K, Sakaguchi S. Impaired T cell receptor signaling and development of T cell-mediated autoimmune arthritis. Immunol Rev. 2020;294(1):164-76

48. Qiu YL, Cheng XN, Bai F, Fang LY, Hu HZ, Sun DQ. Aucubin protects against lipopolysaccharide-induced acute pulmonary injury through regulating Nrf2 and AMPK pathways. Biomed Pharmacother. 2018;106:192-9.

49. Fu C, Zhang X, Lu Y, Wang F, Xu Z, Liu S, Zheng H, Liu X. Geniposide inhibits NLRP3 inflammasome activation via autophagy in BV-2 microglial cells exposed to oxygen-glucose deprivation/reoxygenation. Int Immunopharmacol. 2020;84:106547.

50. Li C, Wang X, Cheng F, Du X, Yan J, Zhai C, Mu J, Wang Q. Geniposide protects against hypoxia/reperfusion-induced blood-brain barrier impairment by increasing tight junction protein expression and decreasing inflammation, oxidative stress, and apoptosis in an in vitro system. Eur J Pharmacol. 2019;854:224-31.

51. Hu R, He Z, Liu M, Tan J, Zhang H, Hou DX, He J, Wu S. Dietary protocatechuic acid ameliorates inflammation and up-regulates intestinal tight junction proteins by modulating gut microbiota in LPS-challenged piglets. J Anim Sci Biotechnol. 2020;11:92.

52. Dai X, Huang Q, Zhou B, Gong Z, Liu Z, Shi S. Preparative isolation and purification of seven main antioxidants from Eucommia ulmoides Oliv. (Du-zhong) leaves using HSCCC guided by DPPH-HPLC experiment. Food Chem. 2013;139(1-4):563-70.

53. Luo J, Tian C, Xu J, Sun Y. Studies on the antioxidant activity and phenolic compounds of enzyme-assisted water extracts from Duzhong (Eucommia ulmoides Oliv) leaves. J Enzyme Inhib Med Chem. 2009;24(6):1280-7.

54. Xu Z, Tang M, Li Y, Liu F, Li X, Dai R. Antioxidant properties of Duzhong (Eucommia ulmoides Oliv) extracts and their effects on color stability and lipid oxidation of raw pork patties. J Agric Food Chem. 2010;58(12):7289-96.

55. Wu D, Yu D, Zhang Y, Dong J, Li D, Wang D. Metabolite Profiles, Bioactivity, and HPLC Fingerprint of Different Varieties of Eucommia ulmoides Oliv: towards the utilization of medicinal and commercial chinese endemic tree. Molecules. 2018;23:8.

56. Zhang Q, Zhu M, Zhang J, Su Y. Improved on-line high performance liquid chromatography method for detection of antioxidants in Eucommia ulmoides Oliver flower. J Biosci Bioeng. 2014;118(1):45-9.
57. Zhang Q, Su Y, Zhang J. Seasonal difference in antioxidant capacity and active compounds contents of Eucommia ulmoides oliver leaf. Molecules. 2013;18(2):1857-68.

58. Yen GC, Hsieh CL. Antioxidant Activity of Extracts from Du-zhong (Eucommia ulmoides) toward Various Lipid Peroxidation Models in Vitro. J Agric Food Chem. 1998;46(10):3952-7.

59. Hsieh CL, Yen GC. Antioxidant actions of du-zhong (Eucommia ulmoides Oliv) toward oxidative damage in biomolecules. Life Sci. 2000;66(15):1387-400.

60. Hong YK, Liu WJ, Li T, She SY. Optimization of extraction of Eucommia ulmoides polysaccharides by response surface methodology. Carbohydr Polym. 2013;92(2):1761-6.

61. Hung MY, Fu TY, Shih PH, Lee CP, Yen GC. Du-Zhong (Eucommia ulmoides Oliv) leaves inhibits $\mathrm{CCl} 4$-induced hepatic damage in rats. Food Chem Toxicol. 2006;44(8):1424-31.

62. Lee MK, Cho SY, Kim DJ, Jang JY, Shin KH, Park SA, Park EM, Lee JS, Choi MS, Lee JS: Du-zhong (Eucommia ulmoides Oliv) cortex water extract alters heme biosynthesis and erythrocyte antioxidant defense system in lead-administered rats. 2005, 8(1): 86-92.

63. Liu H, Li K, Zhao J, Deng W. Effects of polyphenolic extract from Eucommia ulmoides Oliver leaf on growth performance, digestibility, rumen fermentation and antioxidant status of fattening lambs. Anim Sci J. 2018;89(6):888-94.

64. Park SA, Choi MS, Jung UJ, Kim MJ, Kim DJ, Park HM, Park YB, Lee MK. Eucommia ulmoides Oliver leaf extract increases endogenous antioxidant activity in type 2 diabetic mice. J Med Food. 2006;9(4):474-9.

65. Yang J, Kato K, Noguchi K, Dairaku N, Koike T, lijima K, Imatani A, Sekine H, Ohara S, Sasano H, et al. Tochu (Eucommia ulmoides) leaf extract prevents ammonia and vitamin C deficiency induced gastric mucosal injury. Life Sci. 2003;73(25):3245-56.

66. Dotan Y, Lichtenberg D, Pinchuk I. Lipid peroxidation cannot be used as a universal criterion of oxidative stress. Prog Lipid Res. 2004:43(3):200-27.

67. Goyal MM, Basak A. Human catalase: looking for complete identity. Protein Cell. 2010;1(10):888-97.

68. Sheng Y, Abreu IA, Cabelli DE, Maroney MJ, Miller AF, Teixeira M, Valentine JS. Superoxide dismutases and superoxide reductases. Chem Rev 2014;114(7):3854-918.

69. Zeida A, Trujillo M, Ferrer-Sueta G, Denicola A, Estrin DA, Radi R. Catalysis of peroxide reduction by fast reacting protein thiols. Chem Rev. 2019;119(19):10829-55.

70. Lin J, Fan YJ, Mehl C, Zhu JJ, Chen H, Jin LY, Xu JH, Wang HM. Eucommia ulmoides Oliv. antagonizes H2O2-induced rat osteoblastic MC3T3-E1 apoptosis by inhibiting expressions of caspases 3, 6, 7, and 9. J Zhejiang Univ Sci B. 2011;12(1):47-54.

71. Jiang S, Yang Z, Huang L, Yang W, Song D, Liu F, Ge J, Wang Y, Jiang S. Effect of Illicium verum or Eucommia ulmoides leaf extracts on the antistress ability, and mRNA and protein expression of Nrf2 and TNF-alpha in Duroc $\times$ Landrace $\times$ Yorkshire and Chinese native Licha-black nursery piglets. J Anim Physiol Anim Nutr (Berl). 2020;104(4):1085-95.

72. Liu B, Li CP, Wang WQ, Song SG, Liu XM. Lignans Extracted from Eucommia ulmoides Oliv. protects against AGEs-induced retinal endothelial cell injury. Cell Physiol Biochem. 2016;39(5):2044-54.

73. Xiao D, Yuan D, Tan B, Wang J, Liu Y, Tan B. The Role of Nrf2 Signaling Pathway in Eucommia ulmoides flavones regulating oxidative stress in the intestine of piglets. Oxid Med Cell Longev. 2019;2019:9719618.

74. He T, Shen H, Zhu J, Zhu Y, He Y, Li Z, Lu H. Geniposide attenuates cadmiuminduced oxidative stress injury via Nrf2 signaling in osteoblasts. Mol Med Rep. 2019;20(2):1499-508.

75. Ma B, Zhang J, Zhu Z, Bao X, Zhang M, Ren C, Zhang Q. Aucubin, a natural iridoid glucoside, attenuates oxidative stress-induced testis injury by inhibiting JNK and CHOP activation via Nrf2 up-regulation. Phytomedicine. 2019;64:153057.

76. Neri-Numa IA, Pessoa MG, Arruda HS, Pereira GA, Paulino BN, Angolini CFF, Ruiz A, Pastore GM. Genipap (Genipa americana L) fruit extract as a source of antioxidant and antiproliferative iridoids. Food Res Int. 2020;134:109252.

77. Shen B, Zhao C, Wang Y, Peng Y, Cheng J, Li Z, Wu L, Jin M, Feng H. Aucubin inhibited lipid accumulation and oxidative stress via Nrf2/HO-1 and AMPK signalling pathways. J Cell Mol Med. 2019;23(6):4063-75. 
78. Wang H, Zhou XM, Wu LY, Liu GJ, Xu WD, Zhang XS, Gao YY, Tao T, Zhou $Y$, Lu Y, et al. Aucubin alleviates oxidative stress and inflammation via Nrf2-mediated signaling activity in experimental traumatic brain injury. J Neuroinflammation. 2020;17(1):188.

79. Yin F, Liu J, Zheng X, Guo L, Xiao HJB. Bulletin p: Geniposide induces the expression of heme oxygenase-1 via PI3K/Nrf2-signaling to enhance the antioxidant capacity in primary hippocampal neurons. Biol Pharm Bulletin. 2010;33(11):1841-6.

80. Sies H, Berndt C, Jones DP. Oxidative stress. Annu Rev Biochem. 2017:86:715-48

81. Kwon SH, Kim MJ, Ma SX, You IJ, Hwang JY, Oh JH, Kim SY, Kim HC, Lee SY, Jang CG. Eucommia ulmoides Oliv. Bark. protects against hydrogen peroxide-induced neuronal cell death in SH-SY5Y cells. J Ethnopharmacol. 2012;142(2):337-45.

82. Kwon SH, Ma SX, Hong SI, Kim SY, Lee SY, Jang CG. Eucommia ulmoides Oliv. bark attenuates 6-hydroxydopamine-induced neuronal cell death through inhibition of oxidative stress in SH-SY5Y cells. J Ethnopharmacol. 2014;152(1):173-82.

83. Li CP, Qiu GZ, Liu B, Chen JL. Fu HTJNS: Neuroprotective effect of lignans extracted from Eucommia ulmoides Oliv. on glaucoma-related neurodegeneration. Neurol Sci. 2016;37(5):755-62.

84. Guo H, Shi F, Li M, Liu Q, Yu B, Hu L. Neuroprotective effects of Eucommia ulmoides Oliv. and its bioactive constituent work via ameliorating the ubiquitin-proteasome system. BMC Complement Altern Med. 2015;15:151.

85. Kwon SH, Lee HK, Kim JA, Hong SI, Kim SY, Jo TH, Park YI, Lee CK, Kim YB, Lee SY, et al. Neuroprotective effects of Eucommia ulmoides Oliv. Bark on amyloid beta(25-35)-induced learning and memory impairments in mice. Neurosci Lett. 2011;487(1):123-7.

86. Zhou Y, Liang M, Li W, Li K, Li P, Hu Y, Yang Z. Protective effects of Eucommia ulmoides Oliv. bark and leaf on amyloid beta-induced cytotoxicity. Environ Toxicol Pharmacol. 2009;28(3):342-9.

87. Sierksma A, Escott-Price V, De Strooper B. Translating genetic risk of Alzheimer's disease into mechanistic insight and drug targets. Science. 2020;370(6512):61-6.

88. Armstrong MJ, Okun MS. Diagnosis and treatment of parkinson disease: a review. JAMA. 2020;323(6):548-60.

89. Hu W, Wang G, Li P, Wang Y, Si CL, He J, Long W, Bai Y, Feng Z, Wang X. Neuroprotective effects of macranthoin $\mathrm{G}$ from Eucommia ulmoides against hydrogen peroxide-induced apoptosis in PC12 cells via inhibiting NF-kappaB activation. Chem Biol Interact. 2014;224:108-16.

90. Lei S, Wu S, Wang G, Li B, Liu B, Lei XJN: Pinoresinol diglucoside attenuates neuroinflammation, apoptosis and oxidative stress in a mice model with Alzheimer's disease. 2021, publish ahead of print.

91. Wu J, Chen H, Li H, Tang Y, Yang L, Cao S, Qin D. Antidepressant potential of chlorogenic acid-enriched extract from Eucommia ulmoides Oliver Bark with neuron protection and promotion of serotonin release through enhancing synapsin I Expression. Molecules. 2016;21(3):260.

92. Zhou Z, Hou J, Mo Y, Ren M, Yang G, Qu Z, Hu Y. Geniposidic acid ameliorates spatial learning and memory deficits and alleviates neuroinflammation via inhibiting HMGB-1 and downregulating TLR4/2 signaling pathway in APP/PS1 mice. Eur J Pharmacol. 2020;869:172857.

93. Horii Y, Tanida M, Shen J, Hirata T, Kawamura N, Wada A, Nagai K. Effects of Eucommia leaf extracts on autonomic nerves, body temperature, lipolysis, food intake, and body weight. Neurosci Lett. 2010:479(3):181-6.

94. Jin CF, Li B, Lin SM, Yadav RK, Kim HR, Chae HJ. Mechanism of the Inhibitory Effects of Eucommia ulmoides Oliv. Cortex Extracts (EUCE) in the CCl 4-Induced Acute Liver Lipid Accumulation in Rats. Int J Endocrinol. 2013:2013:751854.

95. Lee GH, Lee HY, Park SA, Shin TS, Chae HJ. Eucommia ulmoides leaf extract ameliorates steatosis induced by high-fat diet in rats by increasing lysosomal function. Nutrients. 2019;11:2.

96. Lee HY, Lee GH, Lee MR, Kim HK, Kim NY, Kim SH, Lee YC, Kim HR, Chae HJ. Eucommia ulmoides Oliver extract, aucubin, and geniposide enhance lysosomal activity to regulate ER stress and hepatic lipid accumulation. PLoS ONE. 2013;8(12):e81349.

97. Choi MS, Jung UJ, Kim HJ, Do GM, Jeon SM, Kim MJ, Lee MK. Du-zhong (Eucommia ulmoides Oliver) leaf extract mediates hypolipidemic action in hamsters fed a high-fat diet. Am J Chin Med. 2008;36(01):81-93.
98. Park SA, Choi MS, Kim MJ, Jung UJ, Kim HJ, Park KK, Noh HJ, Park HM, Park YB, Lee JS, et al. Hypoglycemic and hypolipidemic action of Duzhong (Eucommia ulmoides Oliver) leaves water extract in C57BL/KsJdb/db mice. J Ethnopharmacol. 2006;107(3):412-7.

99. Hao S, Xiao Y, Lin Y, Mo Z, Chen Y, Peng X, Xiang C, Li Y, Li W. Chlorogenic acid-enriched extract from Eucommia ulmoides leaves inhibits hepatic lipid accumulation through regulation of cholesterol metabolism in HepG2 cells. Pharm Biol. 2016;54(2):251-9.

100. Gonzalez A, Hall MN, Lin SC, Hardie DG. AMPK and TOR: The Yin and Yang of Cellular Nutrient Sensing and Growth Control. Cell Metab. 2020;31(3):472-92.

101. Gonzalez-Muniesa P, Martinez-Gonzalez MA, Hu FB, Despres JP, Matsuzawa Y, Loos RJF, Moreno LA, Bray GA, Martinez JA. Obesity. Nat Rev Dis Primers. 2017:3:17034

102. Fujikawa T, Hirata T, Wada A, Kawamura N, Yamaguchi Y, Fujimura K, Ueda T, Yurugi Y, Soya H, Nishibe S. Chronic administration of Eucommia leaf stimulates metabolic function of rats across several organs. Br J Nutr. 2010;104(12):1868-77.

103. Hirata T, Kobayashi T, Wada A, Ueda T, Fujikawa T, Miyashita H, Ikeda T, Tsukamoto S, Nohara T. Anti-obesity compounds in green leaves of Eucommia ulmoides. Bioorg Med Chem Lett. 2011;21(6):1786-91.

104. Fujikawa T, Hirata T, Hosoo S, Nakajima K, Wada A, Yurugi Y, Soya H, Matsui T, Yamaguchi A, Ogata M, et al. Asperuloside stimulates metabolic function in rats across several organs under high-fat diet conditions, acting like the major ingredient of Eucommia leaves with anti-obesity activity. J Nutr Sci. 2012;1:e10.

105. Lee MK, Kim MJ, Cho SY, Park SA, Park KK, Jung UJ, Park HM, Choi MS Hypoglycemic effect of Du-zhong (Eucommia ulmoides Oliv) leaves in streptozotocin-induced diabetic rats. Diabetes Res Clin Pract. 2005;67(1):22-8.

106. Jin X, Amitani K, Zamami Y, Takatori S, Hobara N, Kawamura N, Hirata T, Wada A, Kitamura Y, Kawasaki H. Ameliorative effect of Eucommia ulmoides Oliv. leaves extract (ELE) on insulin resistance and abnormal perivascular innervation in fructose-drinking rats. J Ethnopharmacol. 2010:128(3):672-8.

107. Nathan DM. Diabetes: advances in diagnosis and treatment. JAMA. 2015;314(10):1052-62.

108. Do MH, Hur J, Choi J, Kim M, Kim MJ, Kim Y, Ha SK. Eucommia ulmoides ameliorates glucotoxicity by suppressing advanced glycation endproducts in diabetic mice kidney. Nutrients. 2018;10:3.

109. Niu HS, Liu IM, Niu CS, Ku PM, Hsu CT, Cheng JT. Eucommia bark (DuZhong) improves diabetic nephropathy without altering blood glucose in type 1-like diabetic rats. Drug Des Devel Ther. 2016;10:971-8.

110. Jing X, Huang WH, Tang YJ, Wang YQ, Li H, Tian YY, Chen Y, Zhou HH, Ouyang DS. Eucommia ulmoides Oliv. (Du-Zhong) Lignans Inhibit Angiotensin II-Stimulated Proliferation by Affecting P21, P27, and Bax Expression in Rat Mesangial Cells. Evid Based Complement Alternat Med. 2015;2015:987973.

111. Shao P, Zhang JF, Chen XX, Sun PL. Microwave-assisted extraction and purification of chlorogenic acid from by-products of Eucommia ulmoides Oliver and its potential anti-tumor activity. J Food Sci Technol. 2015;52(8):4925-34.

112. Wang Y, Tan X, Li S, Yang S. The total flavonoid of Eucommia ulmoides sensitizes human glioblastoma cells to radiotherapy via HIF-alpha/ MMP-2 pathway and activates intrinsic apoptosis pathway. Onco Targets Ther. 2019;12:5515-24.

113. Fujiwara A, Nishi M, Yoshida S, Hasegawa M, Yasuma C, Ryo A, Suzuki Y. Eucommicin A, a beta-truxinate lignan from Eucommia ulmoides, is a selective inhibitor of cancer stem cells. Phytochemistry. 2016:122:139-45.

114. Yang G, Kyoung Seo E, Lee JH, Young Lee J. Suppression of splenic lymphocyte proliferation by Eucommia ulmoides and genipin. Chem Biodivers. 2015;12(4):538-46.

115. Zhang WH, Liu ZL, Liu CD, Zhu CH. Effect of Eucommia ulmoides Oliv. on SOD activity and a-actin expression in the penile tissues of diabetic rats. Natl J Androl. 2005;1 1:309-13.

116. Zhang WH, Li G, Dong HS, Liu ZL, Xiong CL. The effects of Eucommia ulmoides Oliv. on catching action of diabetic rats and myelinated nerve fibers in penile tissues. Natl J Androl. 2006;12(5):466-9.

117. Fu H, Bai X, Le L, Tian D, Gao H, Qi LX, Hu KP. Eucommia ulmoides Oliv. Leaf Extract Improves Erectile Dysfunction in Streptozotocin-Induced 
Diabetic Rats by Protecting Endothelial Function and Ameliorating Hypothalamic-Pituitary-Gonadal Axis Function. Evid Based Complement Alternat Med. 2019;2019:1782953.

118. Li Y, Koike K, Che Q, Yamaguchi M, Takahashi S. Changes in lactate dehydrogenase and 3-hydroxyacetyl-CoA dehydrogenase activities in rat skeletal muscle by the administration of Eucommia ulmoides OLIVER leaf with spontaneous running-training. Biol Pharm Bull. 1999;22(9):941-6.

119. Li Y, Metori K, Koike K, Che QM, Takahashi S. Improvement in the turnover rate of the stratum corneum in false aged model rats by the administration of geniposidic acid in Eucommia ulmoides Oliver Leaf. Biol Pharm Bull. 1999;22(6):582-5.

120. Ho JN, Lee YH, Park JS, Jun WJ, Kim HK, Hong BS, Shin DH, Cho HY. Protective effects of aucubin isolated from Eucommia ulmoides against UVB-induced oxidative stress in human skin fibroblasts. Biol Pharm Bull. 2005;28(7):1244-8.

121. Zhang L, Ravipati AS, Koyyalamudi SR, Jeong SC, Reddy N, Bartlett J, Smith PT, de la Cruz M, Monteiro MC, Melguizo Á, et al. Anti-fungal and anti-bacterial activities of ethanol extracts of selected traditional Chinese medicinal herbs. Asian Pac J Trop Med. 2013;6(9):673-81.

122. Liu C, Guo FF, Xiao JP, Wei JY, Tang LY, Yang HJ. Research advances in chemical constituents and pharmacological activities of different parts of Eucommia ulmoides. China J Chin Materia Medica. 2020;45:3.

123. Takamura C, Hirata T, Ueda T, Ono M, Miyashita H, Ikeda T, Nohara T. Iridoids from the green leaves of Eucommia ulmoides. J Nat Prod. 2007;70(8):1312-6.

124. Ding YX, Li Q, Zhang H, Kim YH, Dou DQ. Iridoid constituents from the male flower of Eucommia ulmoides and their promotion proliferation on ESF-1. J Asian Nat Prod Res. 2015;17(9):867-75.

125. Hua HM, Yin HQ, Li BQ, Hu B, Pei YH. A new monoterpene from the bark of Eucommia ulmoides. J Asian Nat Prod Res. 2002;4(3):201-4.

126. Huang $Q$, Tan JB, Zeng $X C$, Wang $Y Q$, Zou ZX, Ouyang DS. Lignans and phenolic constituents from Eucommia ulmoides Oliver. Nat Prod Res. 2019;1:1-8.

127. Li C, Li L, Wang C, Yang J, Ye F, Tian J, Si Y, Zhang D. A new ursane-type nor-triterpenoid from the leaves of Eucommia ulmoides Oliv. . Molecules. 2012;17(12):13960-8.

128. Yan J, Shi X, Donkor PO, Zhu H, Gao X, Ding L, Qiu F. Nine pairs of megastigmane enantiomers from the leaves of Eucommia ulmoides Oliver. J Nat Med. 2017;71(4):780-90.

129. Yan JK, Shi XL, Donkor PO, Gao XM, Ding LQ, Qiu F. Two pairs of phenolic enantiomers from the leaves of Eucommia ulmoides Oliver. Nat Prod Res. 2019;33(8):1162-8.

130. Lacey DL, Boyle WJ, Simonet WS, Kostenuik PJ, Dougall WC, Sullivan JK, San Martin J, Dansey R. Bench to bedside: elucidation of the OPGRANK-RANKL pathway and the development of denosumab. Nat Rev Drug Discov. 2012;11(5):401-19.

131. Li Q, Guo G, Meng F, Wang HH, Niu Y, Zhang Q, Zhang J, Wang Y, Dong L, Wang C. A naturally derived, growth factor-binding polysaccharide for therapeutic angiogenesis. ACS Macro Lett. 2016;5(5):617-21.

132. Li Q, Niu Y, Diao H, Wang L, Chen X, Wang Y, Dong L, Wang C. In situ sequestration of endogenous PDGF-BB with an ECM-mimetic sponge for accelerated wound healing. Biomaterials. 2017;148:54-68.

133. Niu Y, Zhang Y, He W, Xing P, Dong L, Li Q, Wang C. Engineering a microcarrier based on a polysaccharide-growth factor complex for enhancing the proliferation of mesenchymal stem cells. Int J Biol Macromol. 2020;155:911-8.
134. Li Q, Feng Y, He W, Wang L, Wang R, Dong L, Wang C. Post-screening characterisation and in vivo evaluation of an anti-inflammatory polysaccharide fraction from Eucommia ulmoides. Carbohydr Polym. 2017;169:304-14.

135. Xiang Y, Huang RH, Liu XZ, Zhang Y, Wang DC. Crystal structure of a novel antifungal protein distinct with five disulfide bridges from Eucommia ulmoides Oliver at an atomic resolution. J Struct Biol. 2004;148(1):86-97.

136. Yan JK, Ding LQ, Shi XL, Donkor PO, Chen LX, Qiu F. Megastigmane glycosides from leaves of Eucommia ulmoides Oliver with ACE inhibitory activity. Fitoterapia. 2017;116:121-5.

137. Wei X, Peng P, Peng F, Dong J. Natural Polymer Eucommia ulmoides Rubber: A Novel Material. J Agric Food Chem. 2021;69(13):3797-821.

138. Li N, Li L, Wu H, Zhou H. Antioxidative property and molecular mechanisms underlying geniposide-mediated therapeutic effects in diabetes mellitus and cardiovascular disease. Oxid Med Cell Longev. 2019;2019:7480512.

139. Liu WZ, Li G. Neuroprotective effects of geniposide on Alzheimer's disease pathology. 2015;26(4):371-83.

140. Shan M, Yu S, Yan H, Guo S, Xiao W, Wang Z, Zhang L, Ding A, Wu Q, Li SFY. A Review on the Phytochemistry, Pharmacology, Pharmacokinetics and Toxicology of Geniposide, a Natural Product. Molecules. 2017;22:10.

141. Zhou YX, Zhang RQ, Rahman K, Cao ZX, Zhang H, Peng C. Diverse Pharmacological Activities and Potential Medicinal Benefits of Geniposide. Evid Based Complement Alternat Med. 2019;2019:4925682.

142. Luo X, Wu J, Li Z, Jin W, Zhang F, Sun H, Shi Y. Safety evaluation of Eucommia ulmoides extract. Regul Toxicol Pharmacol. 2020;1 18:104811.

143. Du KZ, Li J, Wang L, Hao J, Yang XJ, Gao XM, Chang YX. Biosurfactant trehalose lipid-enhanced ultrasound-assisted micellar extraction and determination of the main antioxidant compounds from functional plant tea. J Sep Sci. 2020;43(4):799-807.

144. Huang Y-X, Liu E-W, Wang L, Huo Y, Wang Q, Olaleye O, Wang T, Gao X-M. LC/MS/MS determination and pharmacokinetic studies of six compounds in rat plasma following oral administration of the single and combined extracts of Eucommia ulmoides and Dipsacus asperoides. Chin J Nat Med. 2014;12(6):469-76.

145. Li Y, Gong Z, Cao X, Wang Y, Wang A, Zheng L, Huang Y, Lan Y. A UPLCMS Method for Simultaneous Determination of Geniposidic Acid, Two Lignans and Phenolics in Rat Plasma and its Application to Pharmacokinetic Studies of Eucommia ulmoides Extract in Rats. Eur J Drug Metab Pharmacokinet. 2016;41(5):595-603.

146. Wang JL, Liu EW, Zhang Y, Wang T, Han LF, Gao XM. Validation of a HPLC tandem MS/MS method for pharmacokinetics study of (+)-pinoresinoldi-beta-D-glucopyranoside from Eucommia ulmoides Oliv. extract in rats' plasma. J Ethnopharmacol. 2012;139(2):337-42.

147. Xu W, Deng Z, Guo H, Ling P. A rapid and sensitive determination of aucubin in rat plasma by liquid chromatography-tandem mass spectrometry and its pharmacokinetic application. Biomed Chromatogr. 2012;26(9):1066-70.

\section{Publisher's Note}

Springer Nature remains neutral with regard to jurisdictional claims in published maps and institutional affiliations.

Ready to submit your research? Choose BMC and benefit from:

- fast, convenient online submission

- thorough peer review by experienced researchers in your field

- rapid publication on acceptance

- support for research data, including large and complex data types

- gold Open Access which fosters wider collaboration and increased citations

- maximum visibility for your research: over $100 \mathrm{M}$ website views per year

At BMC, research is always in progress.

Learn more biomedcentral.com/submissions 